\title{
Generation of Genetically-Modified Human Differentiated Cells for Toxicological Tests and the Study of Neurodegenerative Diseases
}

\author{
Stefan Schildknecht, Christiaan Karreman, Dominik Pöltl, Liudmila Efrémova, Cornelius \\ Kullmann, Simon Gutbier, Anne Krug, Diana Scholz, Hanne R. Gerding, and Marcel Leist
}

Doerenkamp-Zbinden Chair for in vitro Toxicology and Biomedicine, Department of Biology, University of Konstanz, Konstanz, Germany

\begin{abstract}
Summary
Human differentiated cell types, such as neurons or hepatocytes, are of limited availability, and their use for experiments requiring ectopic gene expression is challenging. Using the human conditionally-immortalized neuronal precursor line LUHMES, we explored whether genetic modification in the proliferating state could be used for experiments in the differentiated post-mitotic neurons. First, alpha-synuclein (ASYN), a gene associated with the pathology of Parkinson's disease, was overexpressed. Increased amounts of the protein were tolerated without change of phenotype, and this approach now allows further studies on protein variants. Knockdown of ASYN attenuated the toxicity of the parkinsonian toxicant 1-methyl4-phenylpyridinium $\left(M P P^{+}\right)$. Different lentiviral constructs then were tested: cells labeled ubiquitously with green (GFP) or red fluorescent protein (RFP) allowed the quantification of neurite growth and of its disturbance by toxicants; expression of proteins of interest could be targeted to different organelles; production of two different proteins from a single read-through construct was achieved successfully by an expression strategy using a linker peptide between the two proteins, which is cleaved by deubiquitinases; LUHMES, labeled with GFP in the cytosol and RFP in the mitochondria, were used to quantify mitochondrial mobility along the neurites. MPP ${ }^{+}$reduced such organelle movement before any other detectable cellular change, and this toxicity was prevented by simultaneous treatment with the antioxidant ascorbic acid. Thus, a strategy has been outlined here to study new functional endpoints, and subtle changes of structure and proteostasis relevant in toxicology and biomedicine in post-mitotic human cells.
\end{abstract}

Keywords: LUHMES, dopaminergic neurons, alpha-synuclein, neurotoxicity

\section{Introduction}

Cell models of human post-mitotic neurons are in high demand as tools for basic research and for pharmacological and toxicological screening projects. In the field of neuroscience, a widely used model is the PC12 cell line, derived from a rat medullary pheochromocytoma (Greene and Tischler, 1976). This cell line provided valuable insight into various areas of neuroscience research, but its strict dependence on neurotrophins for differentiation and survival is a disadvantage for several applications. In contrast to rat PC12 cells, SH-SY5Y cells are of human origin. These neuroblastoma cells are another prominent example of a well-established cell model in the field of neuroscience (Biedler et al., 1973, 1978). SH-SY5Y are easy to grow but difficult to differentiate into a fully postmitotic state (Påhlman et al., 1984; Lopes et al., 2010). Primary neurons, such as cortical neurons or cerebellar granule cells (CGC), are an alternative to these cell lines (Hatten and Liem, 1981; Hatten, 1985). Besides the difficulty to obtain human primary cells, batch-to-batch variations, contaminations with non-neuronal cells, and the continuous requirement for new source material are critical limitations of primary cell models. In the future, stem cells are likely to become an important source for human cells with precisely defined phenotypes (Leist et al., 2008, 2012; Basketter et al., 2012). Currently available protocols for stem cell-derived neurons are still highly demanding and often show inadequate homogeneity and synchronicity (Johansson et al., 1999; Lee et al., 2010).

Cell lines are characterized by their ability to proliferate over an extended period of time, while mature neurons, per definition, are in a post-mitotic state. This basic contradiction was solved recently by the generation of the LUHMES (Lund human mesencephalic) cell line. Neuronal human precursor cells from ventral mesencephalic tissue of a female fetus were condi-

Received April 4, 2013; accepted in revised form May 30, 2013; Epub June 7, 2013 
tionally immortalized with the v-myc oncogene. Proliferation of the cells can be interrupted by tetracycline-controlled termination of v-myc expression. Addition of tetracycline in combination with neurotrophic mediators enables an exit from the cell cycle and differentiation into a neuronal phenotype (Lotharius et al., 2005). LUHMES are a single cell subclone of MESC2.10 cells that were originally generated as an alternative source of graft material for transplantations in Parkinson's disease (PD) patients (Hansson et al., 2000; Lotharius et al., 2002; Paul et al., 2007). Based on their mesencephalic origin, LUHMES then were introduced as an in vitro PD model (Lotharius et al., 2005). Degeneration in a manner that reflects many events observed in the substantia nigra of PD patients has been examined after exposure of LUHMES to the parkinsonian toxin 1-methyl-4phenylpyridinium $\left(\mathrm{MPP}^{+}\right)$in low micromolar concentrations, to methamphetamine, paraquat, or rotenone (Lotharius et al., 2005; Schildknecht et al., 2009). Under these conditions, progressive degeneration of neurites and ultimately cell death can be observed. Differentiated LUHMES cells are electrically active and express functional dopamine transporter (DAT), vesicular monoamine transporter (VMAT-2), and the PD-related protein alpha-synuclein (ASYN) (Schildknecht et al., 2009, 2011; Scholz et al., 2011). In the brain, ASYN accounts for about $1 \%$ of total protein mass. Although a defined physiological function of ASYN has so far only poorly been described, evidence is accumulating that it is involved in modulating synaptic transmission (Stefanis, 2012). By variations in the differentiation proto$\mathrm{col}$, the cells can acquire a tyrosine hydroxylase $(\mathrm{TH})$ positive - or negative - phenotype (Scholz et al., 2011). Thus, cells not containing dopamine can be easily generated for non PD-related research as a general human neuronal in vitro model. Such an alternative field of application is, e.g., Alzheimer's disease research. Differentiated LUHMES release amyloid beta $(A \beta)$ peptide, as not only amyloid precursor protein (APP; 695 amino acid variant) is endogenously expressed, but also the enzymatic machinery (BACE, $\gamma$-secretase) that is required for sequential cleavage of the precursor (Scholz et al., 2013).

Genetic manipulation of cells by overexpression or knockdown of targets of interest has become a standard method used for mechanistic studies. In many cases, it is easier to generate transgenic/knockout mice as model or cell source, than to modify neurons directly. This has resulted in a high demand for laboratory animals (Leist et al., 2008). Although LUHMES cells show many attractive neuronal aspects that justify their use as in vitro neuronal model, their applicability has been limited due to the difficulties of genetic modifications. Standard methods such as lipofection or electroporation show highly variable success in these cells. We herein introduce methods for reliable overexpression and knockdown of genes of interest in LUHMES. Especially the availability of stable subclones, expressing fluorescent proteins in different compartments, is very useful. Such methods allow real-time tracing of organelles, such as mitochondria, or of proteins, such as ASYN. Methodologies as well as the plasmids and stable LUHMES subclones introduced in this work provide a toolbox that is intended to broaden applicability and acceptance of LUHMES as an in vitro alternative to the use of transgenic rodent models.

\section{Materials and methods}

\section{LUHMES culture}

The cells were derived by conditional immortalization of ventral mesencephalic cells by a LINX v-myc retroviral vector. Myc expression is under control of a minimal CMV promoter. The promoter is activated by a tetracycline-controlled transactivator. Addition of tetracycline terminates v-myc expression and enables exit from the cell cycle (Lotharius et al., 2005; Schildknecht et al., 2009; Scholz et al., 2011). LUHMES were grown at $37^{\circ} \mathrm{C}$ in a humidified $95 \%$ air and $5 \% \mathrm{CO}_{2}$ atmosphere. Propagation of undifferentiated LUHMES was performed by using Nunclon $^{\text {TM }}$ (Nunc, Roskilde, Denmark) cell culture flasks precoated with $50 \mu \mathrm{g} / \mathrm{ml}$ poly-L-ornithine (PLO) and $1 \mu \mathrm{g} / \mathrm{ml}$ fibronectin (Sigma, St. Louis, MO) in $\mathrm{H}_{2} \mathrm{O}$ for at least $3 \mathrm{~h}$ at $37^{\circ} \mathrm{C}$. The coating solution then was removed, culture flasks were washed with $\mathrm{H}_{2} \mathrm{O}$ and air-dried before cell seeding. Cells were grown until a confluency of $80 \%$ was reached, and then passaged 1:10. For cell detachment, 2x ATV-trypsin (136 mM NaCl, $5.4 \mathrm{mM}$ $\mathrm{KCl}, 6.9 \mathrm{mM} \mathrm{NaHCO}$, $5.6 \mathrm{mM}$ D-glucose, $0.54 \mathrm{mM}$ EDTA, $0.5 \mathrm{~g} / \mathrm{l}$ trypsin from bovine pancreas Type-II-S; Sigma) in $\mathrm{H}_{2} \mathrm{O}$ was diluted 1:1 with PBS and incubated for $3 \mathrm{~min}$. Cells were collected in Advanced DMEM/F12 medium (Gibco Invitrogen, Karlsruhe, Germany) and centrifuged at $300 \mathrm{x} g$ for $5 \mathrm{~min}$ at RT. The cell pellet was resuspended in proliferation medium, consisting of Advanced DMEM/F12, 1x N2 supplement (Invitrogen), $2 \mathrm{mM}$ L-glutamine (Gibco), and $40 \mathrm{ng} / \mathrm{ml}$ recombinant bFGF (R\&D Systems, Minneapolis, MN). Cells were grown to a density of $40-50 \%$, the differentiation process then was initiated in cell culture flasks by adding differentiation medium consisting of Advanced DMEM/F12, 1x N2 supplement, 2 mM L-glutamine, $1 \mathrm{mM}$ dbcAMP (Sigma), $1 \mu \mathrm{g} / \mathrm{ml}$ tetracycline (Sigma), and $2 \mathrm{ng} / \mathrm{ml}$ recombinant human GDNF (R\&D Systems). After 2 days in culture flasks, cells were trypsinized as described, counted and seeded at a density of 150,000 cells/ $\mathrm{cm}^{2}$, if not otherwise indicated, in 24-well Nunclon ${ }^{\mathrm{TM}}$ PLO (50 $\mu \mathrm{g} / \mathrm{ml}) /$ fibronectin $(1 \mu \mathrm{g} / \mathrm{ml})$ coated culture plates in differentiation medium. Medium was changed after 2 days; for the experiments presented in this work, no additional medium change was performed. Differentiation following the 2 days in flasks and replating was continued for 4 more days to achieve a total differentiation period of 6 days before the cells were used for experiments.

\section{Western blot analysis}

Cells were lysed in RIPA-buffer (50 mM Tris-base, $150 \mathrm{mM}$ $\mathrm{NaCl}, 1 \mathrm{mM}$ EDTA, $0.25 \%$ sodium deoxycholate, $1 \% \mathrm{NP} 40$, $1 \mathrm{mM} \mathrm{Na}_{3} \mathrm{VO}_{4}, 50 \mathrm{mM} \mathrm{NaF}, \mathrm{pH} 7.5$ ) for $15 \mathrm{~min}$. After removal of cell debris by centrifugation at $1000 \mathrm{x}$ g for $2 \mathrm{~min}$, protein determination was performed using a BCA protein assay kit (Pierce). For Western blot samples, $25 \mu \mathrm{g}$ of total protein was boiled for $5 \mathrm{~min}$ at $95^{\circ} \mathrm{C}$ and loaded on $12 \%$ SDS gels. Proteins were transferred onto nitrocellulose membranes (Amersham, Buckinghamshire, UK), loading and transfer were controlled by brief Ponceau staining, washed membranes then were blocked with $5 \%$ milk in PBS-Tween $(0.1 \%)$ for $2 \mathrm{~h}$. Primary antibodies, diluted in $5 \% \mathrm{BSA} / 0.1 \%$ Tween in PBS were incubated at $4^{\circ} \mathrm{C}$ 
overnight. Following washing steps with PBS-Tween $(0.1 \%)$, horseradish peroxidase-conjugated secondary antibodies were incubated for $1 \mathrm{~h}$ at RT; for visualization, ECL Western blotting substrate (Pierce) was used. Anti-TH antibody was obtained from Chemicon/Millipore (clone 2/40/15, mouse, 1:5,000), antiASYN antibody was from BD (mouse, 1:5,000), anti-GAPDH antibody was from Sigma (mouse, 1:5,000). As secondary antibody, anti-mouse HRP (1:5,000, Jackson Immuno Research) was used.

\section{Reverse transcription quantitative PCR}

The procedure and quantification were performed as described previously (Kremer et al., 2010; Zimmer et al., 2011a). Briefly, total RNA was extracted with TRIzol from Invitrogen (Darmstadt, Germany) and $1 \mu \mathrm{g}$ of total RNA was reverse transcribed with Superscript ${ }^{\mathrm{TM}}$ II Reverse Transcriptase (Invitrogen, Darmstadt, Germany) using random hexamers or oligo-dT-Primer in a $20 \mu 1$ reaction according to the manufacturer's protocol. PCR amplification of the cDNA was quantified using the Platinum ${ }^{\circledR}$ SYBR ${ }^{\circledR}$ Green qPCR SuperMix-UDG kit (Invitrogen, Darmstadt, Germany). The threshold cycle $\left(C_{t}\right)$ was determined for each sample using an iCycler MyiQ qPCR device (BioRad Laboratories, Hercules, CA, USA) and corresponding data analysis software. The housekeeping gene control was GAPDH. Primers (Eurofins MWG Operon, Ebersberg, Germany) were designed using AiO (All in One) bioinformatics software (Karreman, 2002). The following primer sequences were used in the study:

- AADC: sense 5'-GAG TCA CTG GTG CGC CAG GA-3'; antisense 5'-CCG TGC GAG AAC AGA TGG CA-3'

- APP: sense 5'-CGC AGA ACA GAA GAA CAG-3'; antisense 5'-GGC ATC AAC AGG CTC AAC-3'

- ASYN: sense 5'-GGT GTG GCA GAA GCA GCA GG-3'; antisense 5'-CAA TGC TCC CTG CTC CCT CC-3'

- DAT: sense 5'-TGA CTT CTA CCG GCT CTG CG-3'; antisense 5'-AGA AGA CGA CGA AGC CGG AG-3'

- Dopamine receptor $D_{2}$ : sense 5'-GCC GGG TTG GCA ATG ATG CA-3'; antisense 5'-ACG GCG AGC ATC CTG AAC T-3'

- GAPDH: sense 5'-GAA GGT GAA GGT CGG AGT CA-3'; antisense 5'-TTG AGG TCA ATG AAG GGG TC-3'

- Pax 3: sense 5'-GAC TGG CTC CAT ACG TCC TGG TGC-3'; antisense 5'-CGG CTG ATG GAA CTC ACT GAC GG-3'

- Synaptophysin: sense 5'-CGA GGT CGA GTT CGA GTA CC-3'; antisense 5'-AAT TCG GCT GAC GAG GAG TA-3'

- Tau: sense 5'-CCA TGC CAG ACC TGA AGA AT-3'; antisense 5'-CAC ACT TGG ACT GGA CGT TG-3'

- TH: sense 5'-GCG CAG GAA GCT GAT TGC TG-3'; antisense 5'-TGT CTT CCC GGT AGC CGC TG-3'

- VMAT-2: sense 5'-TGG GGA GGT GGC TTT GTG CT-3'; antisense 5'-CCC ATA GAC GGA CAC GTG CC-3'

- v-myc: sense 5'-CAG CCG CCA AGA GGC TAA AG-3'; antisense 5'-TCG TTG TTG GCC ACC TCG GG-3'

The threshold cycles $\left(\mathrm{C}_{\mathrm{t}}\right)$ were determined for each gene, and gene expression levels were calculated as relative expression compared to GAPDH $\left(2^{-(\Delta \mathrm{Ct})}\right)$ or as fold change relative to d0 cells $\left(2^{-(\Delta \Delta \mathrm{Ct})}\right) . \Delta \mathrm{C}_{\mathrm{t}}$ and $\Delta \Delta \mathrm{C}_{\mathrm{t}}$ were calculated using the fol- lowing formulas: $\Delta \mathrm{C}_{\mathrm{t}}=\mathrm{C}_{\mathrm{t}}($ day $\mathrm{X}$, gene $\mathrm{Y})-\mathrm{C}_{\mathrm{t}}$ (day $\left.\mathrm{X}, \mathrm{GAPDH}\right)$. $\Delta \Delta \mathrm{C}_{\mathrm{t}}=\Delta \mathrm{C}_{\mathrm{t}}($ day $\mathrm{X}$, gene $\mathrm{Y})-\Delta \mathrm{C}_{\mathrm{t}}($ day 0 , gene $\mathrm{Y})$.

\section{Immunocytochemistry}

LUHMES (wt or modified) cultures were grown and differentiated on precoated (50 $\mu \mathrm{g} / \mathrm{ml} \mathrm{PLO} ; 1 \mu \mathrm{g} / \mathrm{ml}$ fibronectin) $15 \mathrm{~mm}$ glass cover slips (Menzel, Braunschweig, Germany) in 12-well plastic cell culture plates at $1.3 \times 10^{5}$ cells $/ \mathrm{cm}^{2}$. Cells were washed with PBS and fixed with PBS/4\% paraformaldehyde (PFA) in $2 \%$ sucrose for $15 \mathrm{~min}$ at room temperature, washed twice with $0.05 \%$ PBS-Tween 20, permeabilized with PBS $/ 0.2 \%$ Triton X-100 for 15 min and incubated with PBS/1\% BSA (Calbiochem, San Diego, CA, USA) for $1 \mathrm{~h}$ at room temperature for blocking. Then, the primary antibodies diluted in $2 \% \mathrm{BSA} /$ PBS were added overnight at $4^{\circ} \mathrm{C}$. After 3 washing steps with PBS $/ 0.1 \%$ Tween 20, the secondary antibodies were applied for $1 \mathrm{~h}$ at room temperature. Hoechst-33342 (1 $\mu \mathrm{g} / \mathrm{ml}$, Molecular Probes) was added for $15 \mathrm{~min}$ prior to the final washing step and cover slips then were mounted on glass slides with Fluorsave reagent (Calbiochem). Samples were imaged with an Olympus IX81 inverted epifluorescence microscope (Hamburg, Germany), using a 20x or 40x objective. Image processing was carried out with the Olympus Cell^ ${ }^{\wedge}$ software. The following antibodies were used in the present study: APP (Millipore, 1:1000, mouse); ASYN (BD, 1:500, mouse); $\beta$-III-tubulin (Sigma, 1:500, rabbit); DAT (Alpha Diagnostic, 1:500, rabbit); sAPP $\beta$ (IBL International, 1:50, rabbit); synaptophysin (Synaptic Systems, 1:1.000, mouse); tau (Synaptic Systems, 1:1.000, rabbit); p-tau (Ser396) (Millipore, 1:1.000, rabbit); TH (Chemicon/Millipore, 1:500, mouse); wld (Abcam, 1:500, rabbit).

\section{Cell viability}

Resazurin (Sigma) was added to the cell culture medium in a final concentration of $5 \mu \mathrm{g} / \mathrm{ml}$ and was incubated for at least $30 \mathrm{~min}$ at $37^{\circ} \mathrm{C}$. The fluorescence intensity was measured at $530 \mathrm{~nm}_{\mathrm{ex}}$ and $590 \mathrm{~nm}_{\mathrm{em}}$ with a Tecan Infinite M200 reader as described earlier (Falsig et al., 2004; Zimmer et al., 2011b).

\section{Quantitative analysis of neurite integrity}

For a quantitative assessment of neurite growth, turboRFP expressing cells, predifferentiated for 2 days, were seeded in 96-well Nuclon ${ }^{\mathrm{TM}}$ plates at a density of $100,000 \mathrm{cells} / \mathrm{cm}^{2}$. Analysis was performed by epifluorescence imaging using an automated microplate-reading microscope (Array-Scan VI ${ }^{\circledR}$ HCS Reader, Cellomics, Pittsburgh, PA) equipped with a Hamamatsu ORCA-ER camera (resolution 1024 x 1024; run at $2 \times 2$ binning). Cells were loaded with $1 \mu \mathrm{g} / \mathrm{ml}$ Hoechst dye H-33342 for nuclear DNA staining at $30 \mathrm{~min}$ prior to the imaging scan. Images were collected in two different fluorescent channels using a 20x objective, and excitation/emission wavelengths of: $365 \pm 50 / 535 \pm 45 \mathrm{~nm}$ for $\mathrm{H}-33342$ on channel 1 and $535 \pm 35$ / $590 \pm 35 \mathrm{~nm}$ for turboRFP on channel 2. A fixed exposure time and an intensity histogram-derived threshold for object identification were used. Intensity histogram-derived thresholds were calculated separately for each image, based on the distance of the intensity peaks of background pixels and signal (=neurite) pixels in the histogram. For each well, ten fields of 
$330 \times 330 \mu \mathrm{m}$ size were scanned and the image sets were analyzed using the Thermo Scientific Cellomics ${ }^{\circledR}$ Spot Detector Bioapplication V4 as described (Stiegler et al., 2011). In brief, this is based on an image analysis algorithm that identifies nuclei as objects in channel 1 according to their intensity, size, area, and shape. A "virtual cell soma area = VCSA" was defined around each nucleus based on the identified nuclear area, expanded by $3.2 \mu \mathrm{m}$ into all directions. A "VCS = viable cellular structures" was defined by a segmentation routine based on virtually inflating all nuclei in a homogeneous way until their boundaries touched everywhere. Structure identification in channel 2 was solely performed in the "VNA = virtual neurite area" (VNA = VCS - VCSA). The major discriminator of the spot detection algorithm was "pixel signal intensity" in relation to the close local environment. All neurite-positive pixels over all VNA were summed up and denominated "neurite area."

\section{Analysis of single cell neurites}

A co-culture of d2 LUHMES consisting of a 1:100 turboRFP/ wildtype-LUHMES mixture was seeded at a density of 100,000 cells $/ \mathrm{cm}^{2}$ in 96 -well Nuclon plates. On the day of imaging, cells were stained with $1 \mu \mathrm{g} / \mathrm{ml}$ Hoechst dye H-33342 for $30 \mathrm{~min}$. As for the total neurite growth measurement, the same imaging parameters were chosen for the cell-based neurite feature analysis. Because only a subgroup of cells expresses RFP, a cell-based neuronal profiler algorithm (Thermo Scientific Cellomics ${ }^{\circledR}$ Neuronal Profiling V4) was chosen to analyze single cell features of these RFP-positive cells. This algorithm identifies nuclei as objects in channel 1 according to their intensity, size, area and shape. Identified nuclei in channel 1 are used to select valid cell bodies in channel 2 . The algorithm constructs a test ring around each nucleus mask and places it on top of channel 2 objects - if the overlap between channel 1 and channel 2 is greater than a set assay parameter, these cell bodies will be counted as valid and in our case only RFP expressing cells will show an overlap at all. To determine the boundaries of cell bodies and their neurites, a demarcation value is chosen so that roughly the half-width of the neurites equals the assay parameter. The bigger this value is chosen, the rounder the cell body gets and the more processes will be counted as neurites. To create the neurite mask, the neurite detection method is based on the removal of local background and a cutoff size of the neurites to be detected. For neurite feature analysis, different parameters can be optimized, like neurite tracing parameters, branch point and cross point settings, and resolving parameters of multiple traced neurites. These parameters have to be adapted for different biologies to improve correct neurite feature identification.

\section{Cloning of lentiviral constructs}

The 2A sequence of porcine teschovirus-1 was cloned using two synthetic oligonucleotides. Upper strand: 5'-GAT TCC CGG GCT AGC CAC AAA CTT CAG CCT GCT GAA GCA AGC AGG TGA TGT AGA GGA GAA CCC CGG TCC CGG AAG CGG CCT A-3' and lower strand: 5'-CCG GTA GGC CGC TTC CGG GAC CGG GGT TCT CCT CTA CAT CAC CTG CTT GCT TCA GCA GGC TGA AGT TTG TGG CTA GCC CGG-3'. The mitochondrial targeting signal was cloned using two complementary oligonucleotides: 5'-ATG TCC GTC CTG ACG CCG CTG CTG CTG CGG GGC TTG ACA GGC TCG GCC CGG CGG-3' and 5'-TAA CGA ATG GAT CTT GGC GCG CGG CAC TGG GAG CCG CCG GGC CGA GCC TGT CAA-3'. The human ubiquitin sequence was isolated using PCR on the pExoIN construct (Trenzyme GmbH, Konstanz, Germany) using the oligos: 5'-TGT ACA TGG GAT CTA TGC AGA TTT TC-3' and 5'-CTC GAG TTA AAC TAG TTT CGA AGA CAA CAT GCC ACC TCT AAG ACG GAG-3'. All expression constructs are based on the lentiviral vector $\mathrm{pHsCXW}$ (Leander Johansen et al., 2005). Two basic expression vectors were created. These contain either the combinations eGFP-Ubi or the combination tRFP-2A-Ubi directly behind the CMV promoter. The gene of interest (G.O.I.) can be cloned using the unique restriction enzymes SexAI and XhoI. These sites were incorporated into the various DNA fragments via PCR. Generally two oligonucleotides were designed, the first consisting of the first 20 coding bases of the gene extended at the 5' end with the end of the ubiquitin gene: 5'-ACC TGG TGC TCC GTC TTA GAG GTG GCATG-N $17-3$ '. The SexAI site is underlined. The second primer consisted of the last 20 bases of the various genes including a stopcodon followed by a XhoI site: 5'-CTC GAG TTA-N $17-3$.' The XhoI site is underlined.

\section{Lentivirus production and generation of stably expressing LUHMES subclones}

For the production of lentiviruses, typically two T175 flasks were seeded with $2.5 \times 10^{7} \mathrm{HEK} 293-\mathrm{FT}$ cells in $20 \mathrm{ml}$ DMEM/ Glutamax with $1 \%$ Pen/Strep and $10 \%$ FCS each. The next day the medium was exchanged for fresh medium. The cells were transformed using the calcium-phosphate precipitation method. Forthis, a mixture of $27 \mu$ glentiviral vector(LeanderJohansenetal., 2005), $12 \mu \mathrm{g} \mathrm{pMDG}$ (envelope vector, http://www.addgene.com), $19 \mu \mathrm{g}$ pBR $\Delta 8.91$ (packaging vector) (Vergo et al., 2007; Scholz et al., 2011), and $215 \mu 12 \mathrm{M} \mathrm{CaCl}_{2}$ in a total volume of $1.75 \mathrm{ml}$ was added dropwise to a $2 \mathrm{x}$ HBS solution $(50 \mathrm{mM}$ HEPES, $280 \mathrm{mM} \mathrm{NaCl}$, and $1.5 \mathrm{mM} \mathrm{Na} 2 \mathrm{HPO}_{4}$; $\mathrm{pH}$ 6.95) while vortexing. Precipitation was allowed by incubating the mixture at RT for $35 \mathrm{~min}$. Precipitates were checked using a microscope and subsequently added dropwise on the plated HEK293-FT cells. After overnight incubation, the medium was changed for $20 \mathrm{ml}$ proliferation medium (for LUHMES: Proliferation medium: Advanced DMEM/F12 with $2 \mathrm{mM} \mathrm{L-}$ glutamine, 1xN2 supplement, $40 \mathrm{ng} / \mathrm{ml}$ recombinant bFGF). If a fluorescent protein was encoded by the construct, cells were checked at this point by fluorescence microscopy. After $24 \mathrm{~h}$ production, the supernatant was harvested, centrifuged at $4^{\circ} \mathrm{C}$ for $10 \mathrm{~min}$ at $3,000 \mathrm{x} \mathrm{g}$ to remove dead cells and finally filtrated through a $0.45 \mu \mathrm{m}$ filter. To the clear solution 1/5 volume of PEG 10,000 solution (40\%) (Sigma) was added, mixed thoroughly, and allowed to precipitate overnight at $4{ }^{\circ} \mathrm{C}$. Viruses were concentrated by centrifugation at $1,500 \mathrm{x} \mathrm{g}$ for $30 \mathrm{~min}$ at $4^{\circ} \mathrm{C}$ and the viral pellet was resuspended in $1 / 100$ of the original volume. The final virus stock was aliquoted (e.g., $20 \mu \mathrm{l}$ ) and stored at $-80^{\circ} \mathrm{C}$.

Undifferentiated LUHMES cells were transduced by incubation for $16 \mathrm{~h}$ with virus-containing supernatant $\left(10^{6}\right.$ infectious 
particles $/ \mathrm{ml}$ ), followed by a change to virus-free fresh proliferation medium. A GFP or RFP-positive cell pool was obtained by FACS sorting (BD FACS ARIA II). The cells were enzymatically dissociated with $0.05 \%$ trypsin (Sigma-Aldrich, St Louis, MO, USA) and filtered through a $70 \mu \mathrm{m}$ cell strainer, washed once with PBS, centrifuged and resuspended in PBS/2\% FCS with a cell density of $10^{7}$ cells $/ \mathrm{ml}$ before they were subjected to FACS sorting. Non-transfected cells were used as control. Following FACS separation, single cell colonies were generated. Due to the localization of the G.O.I. and eGFP, respectively tRFP, on one plasmid, the intensity of the fluorescence signal obtained from the different clones directly correlates with the degree of G.O.I. overexpression.

\section{siRNA mediated knockdown of ASYN}

LUHMES were differentiated for 2 days according to the standard protocol. For transfection, solution A, consisting of $4 \mu 1$ Lipofectamine $^{\mathrm{TM}} 2000$ (Life Technologies, Carlsbad, CA, USA) and $150 \mu 1$ Opti-MEM ${ }^{\circledR}$ (Life Technologies, CA, USA) were mixed and incubated for $5 \mathrm{~min}$ at room temperature. Solution B consists of $50 \mathrm{nmol}$ of the respective siRNA and $150 \mu 1$ Opti-MEM ${ }^{\circledR}$. After 5 min incubation, both solutions were combined, transferred to 6-well plates, and incubated for $20 \mathrm{~min}$. The amounts indicated refer to one well of a 6-well plate. Predifferentiated, trypsinized LUHMES were then added in a volume of $1.7 \mathrm{ml}$ differentiation medium to the siRNA containing solution at a density of $1.5 \times 10^{6}$ cells/well (6-well plate) and thoroughly mixed. After 4 more days of differentiation, cells were harvested and subjected to Western blot analysis. siRNA oligonucleotides were obtained from Ambion (Austin, USA) and were based upon the sequences published by Fountaine and Wade-Martins (2007). Scramble sense: 5'-GCG ACG UUC CUG AAA CCA CTT-3', scramble antisense: 5'-GUG GUU UCA GGA ACG UCG CTT-3'; snca1 sense: 5'-GGA AAG ACA AAA GAG GGU GTT-3', snca1 antisense: 5'-CAC CCU CUU UUG UCU UUC CTG-3'; snca2 sense: 5'-GGG UGU UCU CUA UGU AGG CTT-3', and snca2 antisense: 5'-GCC UAC AUA GAG AAC ACC CTT-3'.

\section{Time lapse microscopy}

Mitochondrial transport dynamics were detected in fully differentiated (d6) mixed cultures of $4 \%$ eGFP/mito-tRFP-overexpressing LUHMES cells mixed with wildtype cells. Single cell time lapse imaging was performed for $247 \mathrm{~s}$ in intervals of $13 \mathrm{~s}$ with a Nikon BioStation IM inverted epifluorescence microscope (Nikon Instruments Europe B.V, Amstelveen, Netherlands) equipped with a $5 \% \mathrm{CO}_{2} / 37^{\circ} \mathrm{C}$ controlled chamber and a 40x 0.8 NA air objective. For maximal comparability, 2-3 samples (e.g., controls and $\mathrm{MPP}^{+}$treated cells) were placed simultaneously into the imaging station and samples from every condition were measured alternately. Each biological experiment consisted of 5-10 technical replicates. For image analysis, kymographs (graphical representations of spatial position over time) based on the data obtained from single cell time lapse experiments were created using ImageJ Software (NIH, Bethesda, USA). First, a $100 \mu \mathrm{m}$ region of interest (ROI) along the neurite with a gap of $10 \mu \mathrm{m}$ between cell body and neurite was manu- ally defined by the segmented line tool. In all cases, anterograde direction was chosen for ROI definition. This ROI was depicted as a straight horizontal line for every time point, ordered graphically from top to bottom by applying the reslice option for the ROI at every measured time point. To calculate mitochondrial velocity, diagonal lines were drawn for each moving mitochondrion in the kymograph and analyzed by calculating the slope with the macro-plugin Kymo Line ROI written by Felix Schöneberger, Bioimaging Center (BIC), Konstanz, Germany. Total numbers of mitochondria were manually counted in the kymograph.

\section{AMAXA nucleofection}

LUHMES were differentiated as described. After two days of differentiation, cells were trypsinized as described and counted. Cells were centrifuged to remove remaining medium and 1.5 million cells were resuspended in $90 \mu 1$ Nucleofector solution from the AMAXA Basic Nucleofector Kit Primary Neurons (VPI-1003, Lonza, Basel, Switzerland). $10 \mu 1$ plasmid solution was added, containing $2.5 \mu \mathrm{g}$ GFP control plasmid (Nucleofector Kit, Lonza, Basel, Switzerland) and $2.5 \mu \mathrm{g}$ ATF4-Luc reporter plasmid (Vattem and Wek, 2004). The resulting cell suspension was transferred into an AMAXA cuvette (Lonza, Basel, Switzerland). Cells were transfected using program C-013 of the AMAXA nucleofector I. After nucleofection, $900 \mu 1$ RPMI 1640 (Gibco Invitrogen, Karlsruhe, Germany) containing 10\% FCS (PAA, Pasching, Austria) was added to the cuvette, cells of different transfections were pooled, and cell number per ml was determined by counting. Cells were seeded at a density of 150,000 cells $/ \mathrm{cm}^{2}$ into 6 -well plates already containing $2 \mathrm{ml}$ differentiation medium. $16 \mathrm{~h}$ after transfection, efficiency was monitored by fluorescence microscopy and the medium was changed. ATF activation was monitored measuring luciferase activity by using Pierce Firefly Luciferase Flash Assay Kit (Thermo Scientific, Rockford, USA) according to the manufacturer instructions with a Tecan Infinite M200 reader.

\section{Statistics}

Toxicological data were confirmed in independent biological experiments (Leist et al., 2010, 2012). Values are expressed as the means \pm SD $(n \geq 3)$. Data were analyzed by one-way ANOVA or Student's t-test as appropriate; differences between treatments were determined by Bonferroni's or Dunnet's post hoc tests (Prism software). Means were considered statistically significant at $\mathrm{p}<0.05$.

\section{Results and discussion}

Strategies to generate genetically modified human neurons Upon addition of tetracycline, post-mitotic, differentiated neurons can be generated from the LUHMES cell line (Schildknecht et al., 2009, 2013; Scholz et al., 2011). To render these cells more useful for biochemical research, methods for stable overexpression of a G.O.I., respectively knockdown of endogenous gene expression, are desirable. As classical methods for the expression of a G.O.I., such as lipofection or nucleoporation, are 
hard to apply to LUHMES cells, we developed protocols for lentiviral gene transfer. We compared the efficiency of lentiviral gene transfer at different stages of LUHMES differentiation. With fully differentiated cells, only moderate infection rates and heterogeneous expression levels were observed. Therefore, we developed a strategy to transduce the cells in the proliferating state followed by enrichment/purification of the desired cell population. By this approach, homogenous populations of cells were obtained and a broad range of example applications is presented in this work.

Incubation of proliferating LUHMES with lentiviral particles leads to a mixed cell population of untransfected cells, and cells with varying degrees of G.O.I. integration (Fig. 1A). In a first selection step, untransfected cells were eliminated by making use of the introduced fluorescence groups (eGFP, DS Red, turbo RFP; see Fig. 1B) and/or the introduced resistances (hygromycin, blasticidine S, puromycin; see Fig. 1B). Important to note is the fact that LUHMES originally were generated by applying neomycin resistance, which excludes it from further use for selection of transfectants. The cells selected via fluorescence or resistance were all successfully transduced, but the expression levels per cell varied, depending on the number of constructs incorporated in a single cell, and on the efficiency of transcription that depends on the site of integration into the genome. In order

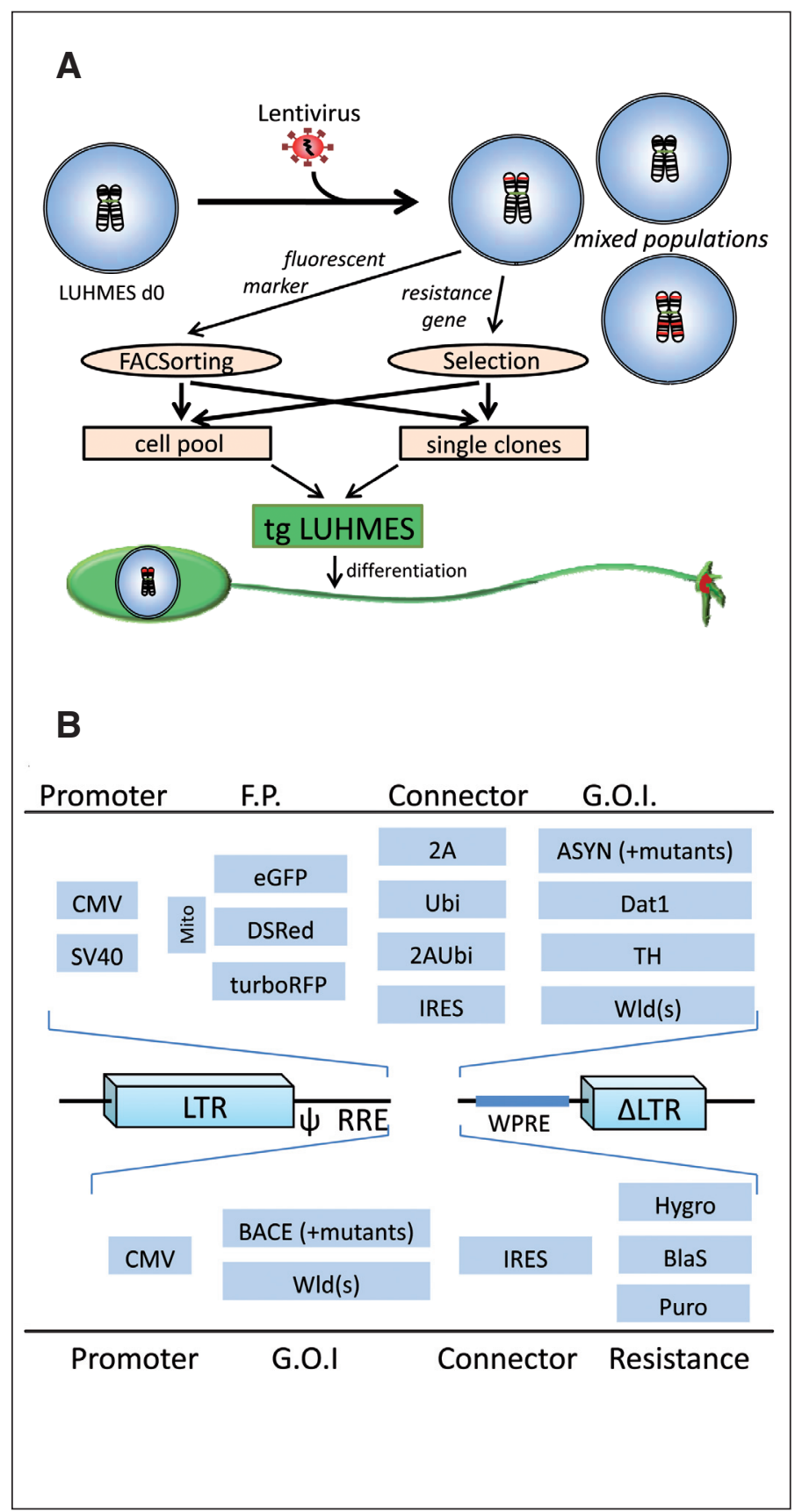

Fig. 1: Strategy for the generation of transgenic LUHMES subclones via lentiviral infection

(A) Proliferating LUHMES cells (d0) were infected with recombinant lentiviruses. The resulting mixed cell pool comprised uninfected cells, cells with a single integration, and cells with multiple integrations. Depending on the marker gene incorporated into the virus, either FAC-sorting or antibiotic selection was performed to enrich the cells that were infected and showed a corresponding expression. Cell lines obtained by either selection strategy can be kept in culture, expanded to any desirable number, and can be differentiated into mature dopaminergic neurons using the standard protocol established previously for LUHMES cells.

(B) Different strategies were used to link the expression of two genes in one expression vector. The viruses used in this study all had the same backbone containing a 5' part consisting of the Long Terminal Repeat (LTR) of HIV followed by the packaging sequence $(\psi)$ and the Rev response element (RRE). The 3' end of the constructs featured the Woodchuck Hepatitis Virus Posttranscriptional Regulatory Element (WPRE) and the 3' LTR with a deletion disabling the promoter sequence (suicide vector). The various payloads of these constructs all were constructed in a cassette-like manner. All of these cassettes can be freely exchanged. The viruses used in FAC-sorting all contained an internal promoter (the cytomegalovirus immediate early promoter (CMV) or that of Simian Virus 40 (SV40), a fluorescent protein (FP), a linking sequence (connector), and the Gene-Of-Interest (G.O.I.). Most of the constructs used a single open reading frame approach. The gene for the marker and that encoding the G.O.I. were cloned in frame, resulting in translation into a single long polypeptide. To study mitochondria, some constructs contain the mitochondrial targeting sequence of cytochrome c oxidase subunit $8 \mathrm{~A}$ at the 5' end of the FP. Genes successfully expressed comprised alpha-synuclein (ASYN), the dopamine transporter (Dat1), tyrosine hydroxylase (TH), the "Wallerian degeneration gene" (wld(s)), and beta secretase (BACE). The viruses that can be selected directly with antibiotics all were based on a bicistronic mRNA expressing the G.O.I. and the selectable gene coupled by an IRES. Viruses with three different genes that confer resistance were tested. These genes were hygromycin B phosphotransferase (Hygro), Blasticidin S deaminase (BlaS) and puromycin acetyltransferase (puro). Abbreviations: eGFP, enhanced green fluorescent protein; DS red, Discosoma sp. red fluorescent protein; turboRFP, turbo red fluorescent protein; Ubi, ubiquitin; IRES, internal ribosome entry site. 
to obtain more homogeneous subcultures, cells were diluted to the single cell level, and then propagated. By this method, it was possible to obtain subclones that expressed the G.O.I. at different levels.

For maximal flexibility of the overexpression method, we constructed a lentivirus-based system comprising a promoter region, various fluorescent markers, a connector, and finally the G.O.I., arranged in cassette-like building blocks. The cassettes, as indicated in Figure 1B, can be freely exchanged. The fluorescence group is encoded on the same mRNA as the G.O.I. Therefore, fluorescence intensities of infected cells should directly correlate with G.O.I. expression. Three different connector sequences were applied. The smallest one (19 aa) was the 2A moiety of porcine teschovirus-1 (PTV2A). The 2A sequences are thought to cause the ribosome to "skip" during the elongation. This is assumed to prevent the formation of a link between the nascent peptide and the following amino acid without stopping the translational machinery. The overall result is the production of two proteins from one open reading frame (Donnelly et al., 2001). Another connector was the human ubiquitin gene (Ubi), consisting of the complete sequence of the monomer (76 aa). With this method, a single fusion protein is produced, consisting of three parts: the fluorescence moiety, followed by ubiquitin, and finally the G.O.I. Ubiquitin is recognized by cellular hydrolases and cleaved at its $\mathrm{C}$-terminus, thereby liberating the
G.O.I. (Matentzoglu and Scheffner, 2009). As a third linker, fusing the marker and G.O.I. proteins, we used a combination of $2 \mathrm{~A}$ and Ubi. This was necessary for fusion protein constructs containing either DS Red (Discosoma sp. red) or tRFP (turbo red fluorescent protein) at their N-terminus. In such cases, the C-terminal G.O.I. protein was efficiently released as desired. However, the remaining fusion product of DS Red or tRFP and ubiquitin aggregated within the expressing cells. To circumvent this problem, the $2 \mathrm{~A}$ sequence was incorporated between the fluorescent protein and ubiquitin. This system allowed high rates of ubiquitin hydrolase mediated cleavage of the G.O.I. protein without significant aggregation of the released fluorescent protein. This observation is of particular relevance when protein aggregation is a part of the intended studies, e.g., when aggregation-prone proteins associated with neurodegenerative diseases are studied. Another way to link the expression of two or more genes is the use of a polycistronic mRNA. This option was also realized by inserting the internal ribosome entry site (IRES) of encephalomyocarditis virus between the fluorescent protein and the G.O.I. This construct allows the synthesis of a single mRNA, coding for the fluorescence group and the G.O.I. As the IRES site offers a second protein translation start site, it enables separate translation of the fluorescence protein and the G.O.I. from one mRNA (Jang et al., 1988), but not necessarily at a 1:1 ratio. The scheme in Figure $1 \mathrm{~B}$ provides an overview of

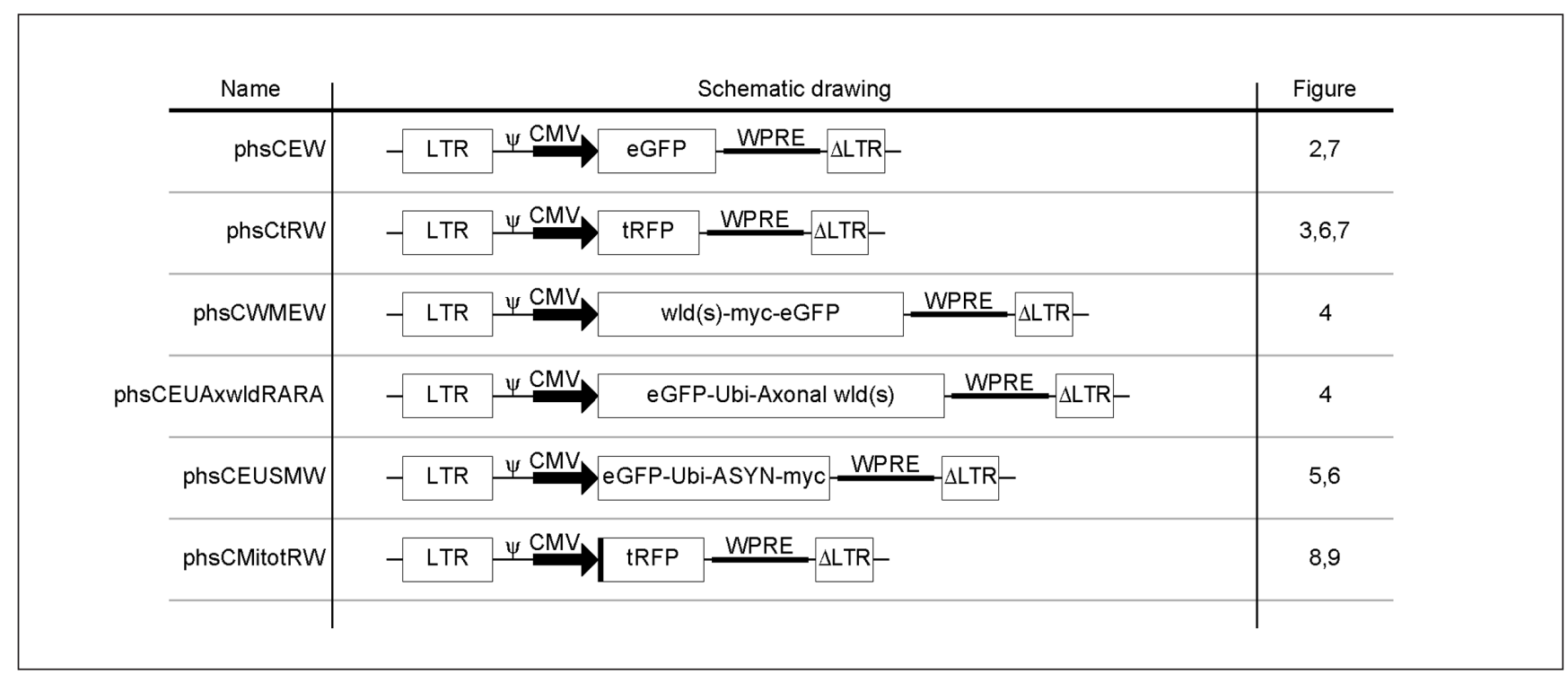

Tab. 1: Overexpression constructs used in the present study

The general design of the viruses used to modify LUHMES cells is depicted in Fig. 1. The viruses used to generate the various cell lines presented in the figures of this article are listed in this table.

Abbreviations: LTR, long terminal repeat, CMV, cytomegalovirus immediate early promoter; WPRE, Woodchuck Hepatitis Virus (WHP) Posttranscriptional Regulatory Element; $\triangle \mathrm{LTR}$, LTR with deletion in the U3 region (suicide virus); eGFP, enhanced Green Fluorescent Protein; tRFP, turbo Red Fluorescent Protein; wld(s)-myc-eGFP, gene for a fusion protein consisting of the Wallerian degeneration gene wld(s) fused to the sequence encoding the myc tag (EQKLISEEDL) and the gene encoding eGFP; eGFP-Ubi-Axonal wld(s), gene encoding a fusion protein consisting of eGFP fused to the human gene for ubiquitin and the gene for wld(s) that was modified for axonal targeting. Note that cell hydrolases will release the axonal wld(s) protein; eGFP-Ubi-ASYN-myc, gene encoding a fusion protein consisting of eGFP fused to the human gene for ubiquitin and the gene for human ASYN followed by a myc-tag. Note that cellular hydrolases will release the myc-tagged ASYN; tRFP with black box at the 5' end; tRFP gene with a mitochondrial targeting sequence (MSVLTPLLLRGLTGSARRLPVPRAKIHSLK) at its 5' end. 
the cassette-like structure and the respective elements available in our laboratory. The constructs used in the present study are listed in Table 1.

\section{Phenotypic markers used for characterization of transgenic LUHMES cells}

Generation of subclones from single cells can lead to cells with a phenotype that differs from the starting population, independently of the G.O.I. inserted. Therefore, new cell lines need to be tested on the mRNA and/or protein level for a reference set of characteristic markers. A pool of GFP-expressing LUHMES expanded for 10 passages was chosen as example (Fig. 2A). For an overview on how the differentiation process affects the expression of a set of target genes associated with Parkinson's and Alzheimer's disease, mRNA expression was analyzed in proliferating (d0) and differentiated cells (d6). Some markers were measured both after normal differentiation and after differentiation in the absence of cAMP/GDNF (-/-). This latter protocol is known to affect expression of tyrosine hydroxylase $(\mathrm{TH})(\mathrm{Scholz}$ et al., 2011). Under (-/-) conditions, TH was almost completely absent on the mRNA and protein level. The alternative differentiation protocol (-/-) represents a useful tool that can be applied when cells not containing dopamine are desired. A qualitative overview of phenotypic markers of GFP expressing cells is pre- sented in Figure 2B. It resembled those of published data sets of untransfected LUHMES (Scholz et al., 2011, 2013).

The markers listed in Figure 2B are meant as guidance for quick characterizations. More extensive characterizations, such as cytogenetic analysis or comprehensive omics data may be required in some cases. Our experience with LUHMES cells suggests that expression of G.O.I. remained stable over many cell passages when cells were maintained according to the standard proliferation/differentiating protocol and in the absence of additional selection pressure. LUHMES, originally designed as an in vitro model for Parkinson's disease, may therefore be broadly used as a general human neuronal cell model with many experimental options offered by the expression of different G.O.I.'s and the two differentiation protocols. If desired, tetracycline may be removed for such experiments on d6, as the LUHMES cells remain postmitotic for at least 4 days after the transgene has been switched off.

\section{Fluorescence labeled cells for analysis of neuronal morphology and neurite growth}

Cell death assays, such as the resazurin reduction assay or the lactate dehydrogenase release assay, are not sufficiently sensitive to measure all types of neurotoxicity (van Thriel et al., 2012). When neurons are affected by a toxicant, functional impairment
A

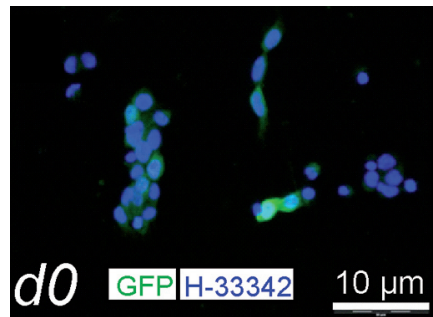

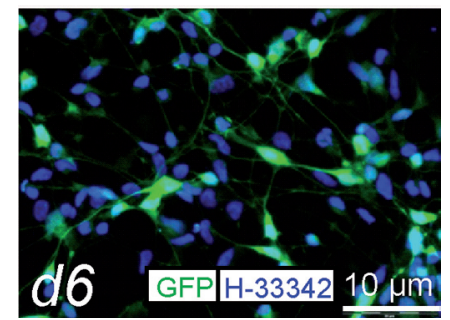

\begin{tabular}{|c|c|c|}
\hline B & $\begin{array}{l}\text { expre } \\
d 0\end{array}$ & ion \\
\hline$A P P^{*}$ & low & high \\
\hline$A \beta^{*}$ & n.d. & low \\
\hline SAPP $\beta^{*}$ & n.d. & low \\
\hline $\operatorname{tau}^{*}$ & low & high \\
\hline$p-$ tau $_{\text {ser } 396}{ }^{*}$ & n.d. & low \\
\hline Pax 3* & high & low \\
\hline v-Myc & low & n.d. \\
\hline$A S Y N^{*}$ & low & high \\
\hline$D A T^{*}$ & n.d. & low \\
\hline synaptophysin & low & high \\
\hline$T H^{*} \quad-/$ & n.d. & n.d. \\
\hline$T H^{*} \quad+/+$ & n.d. & high \\
\hline
\end{tabular}

\section{Fig. 2: Phenotypes of proliferating and differentiated LUHMES}

(A) Representative images of undifferentiated (d0) and fully differentiated (d6) GFP-expressing LUHMES. Nuclei were stained with Hoechst $\mathrm{H}-33342(1 \mu \mathrm{M})$, images were obtained with live cells. (B) Overview of marker expression during LUHMES differentiation. Protein or mRNA was collected on day 0 or on day 6 of differentiation. Targets analyzed on the mRNA level are indicated in red and italics; markers analyzed on the protein level are highlighted by a blue asterisk. Targets investigated by PCR with threshold amplification cycles higher than 35 were considered non-detectable (n.d.). (-/-) or (+/+) indicates the differentiation of LUHMES in the absence (-/-) or presence (+/+) of cAMP/GDNF. Abbreviations: APP, amyloid precursor protein; $A \beta$, amyloid $\beta$; sAPP $\beta$, soluble amyloid precursor protein $\beta$; p-tau, phosphorylated tau; Pax 3, paired box 3 (gene); myc, myelocytomatosis viral oncogene homolog; TH, tyrosine hydroxylase; ASYN, alpha-synuclein; DAT, dopamine transporter; GFP, green fluorescent protein; $\mathrm{H}-33342$, Hoechst dye. 
or small changes in neurite integrity can lead to a complete loss of function in an organism, even in the absence of neuronal death (Berliocchi et al., 2005). Automated methods for assessment of neurite growth require fluorescent labeling of cells. Use of cells expressing fluorescent proteins would allow live time-lapse imaging and at the same time avoid the necessity of a staining step with all its associated manipulations. For this purpose, strongly tRFP-expressing LUHMES were generated. For neurite integrity assessment, RFP-LUHMES were treated from $\mathrm{d} 2$ to $\mathrm{d} 3$ of differentiation with a set of compounds that were recently identified to modulate neurite outgrowth: U-0126 and bis-1 (bisindolylmaleinide 1) negatively affect pathways of neurite outgrowth control; Y-27632 is a Rho kinase inhibitor known to promote neurite growth (Stiegler et al., 2011). Following treatment with the compounds, the cells were analyzed by an automated microscope system in combination with an algorithm for image analysis that allows the specific detection of total neurite area. Representative example pictures are shown in Figure 3A. The effect of the tool compounds on neurite growth was directly compared with effects on cell viability, as assessed by counting the number of RFP-positive cells with morphologically normal nuclei (Fig. 3B). Pilot experiments had shown that RFP is only expressed in viable cells. Under the conditions employed, no obvious cytotoxicity was observed, whereas the analysis of neurite area clearly showed the expected effects of chemicals on neurite outgrowth (Fig. 3B). Such a non-invasive neurite growth assay may allow neurodevelopmental or neurotoxicity studies, with the potential to identify subtle changes in the neurite network that would not be detected by standard cell viability assays.

In the course of our studies with LUHMES cells, we observed that cell density can have a significant influence on the outcome of a study. Standard culture conditions provided stable and viable neurons, but they resulted in high cell densities at which single neurites can no longer be assigned to their originating soma. To obtain information on whether a compound influences total neurite length or the branching of neurites (both would be measured as a decrease in neurite area), conditions are required under which neurites can clearly be assigned to a single neuron. In order to allow studies on single cells in an environment of standard LUHMES cell density, tRFP-LUHMES were mixed with nonfluorescent wildtype LUHMES at a ratio of $2 \% / 98 \%$ (Fig. 3C). With this method, tRFP-labeled neurites can clearly be assigned to their corresponding cell body. Figure $3 \mathrm{C}$ illustrates control cells and cells treated with a mixture of compounds that we have found to be particularly useful for such proof-of-concept experiments, as it is well tolerated by cells over extended time periods. Low concentrations of rotenone $(50 \mathrm{nM})$ were combined with narciclasine $(25 \mathrm{nM})$ for $72 \mathrm{~h}$. Narciclasine promotes activation
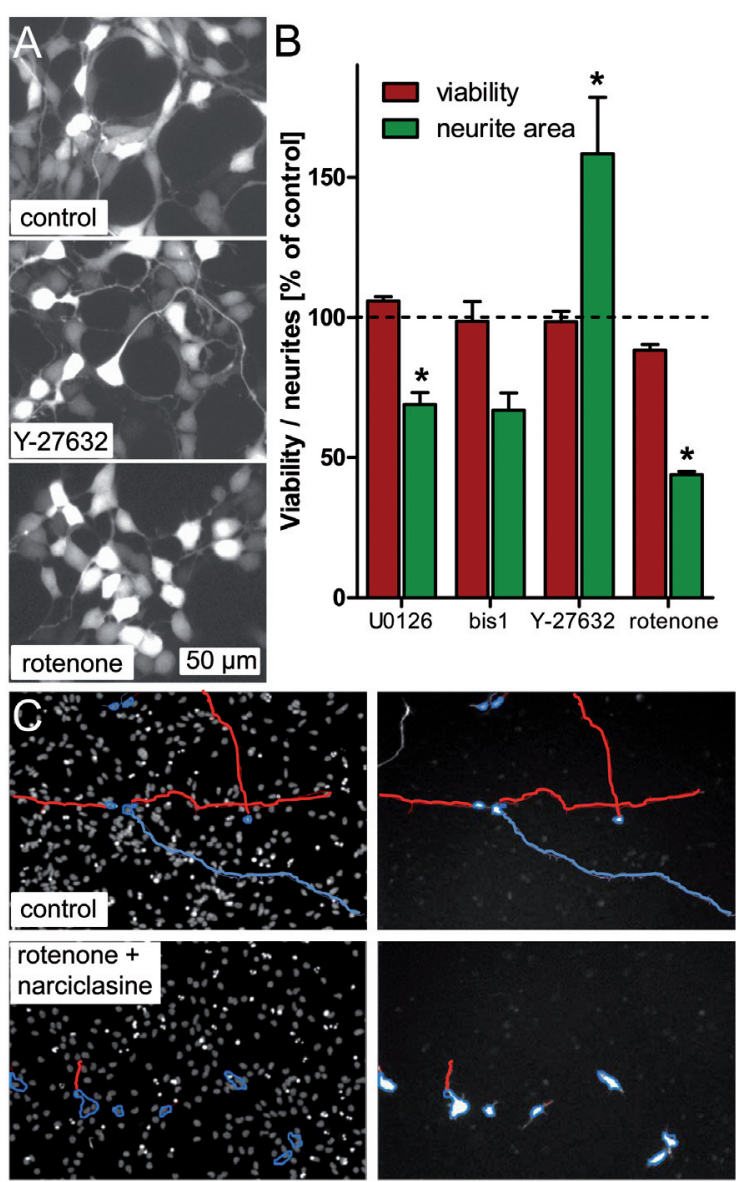

Fig. 3: Fluorescent LUHMES to analyze neurite growth and developmental neurotoxicity

TurboRFP expressing cells were replated at $\mathrm{d} 2$ into a 96-well plate at a density of $3 \times 10^{4} /$ well, and exposed to chemicals for $24 \mathrm{~h}$. Then, cells were stained with $\mathrm{H}-33342$ and imaged on an automated microscope. The number of viable cells/field and the total neurite area/field were automatically detected and quantified on a high content screening system. (A) Example images show cells treated with solvent (control) or with either $7 \mu \mathrm{M}$ Y-27632 or $0.1 \mu \mathrm{M}$ rotenone. (B) Quantitative assessment of neurite integrity and viability of d3 LUHMES treated for $24 \mathrm{~h}$ with $12.5 \mu \mathrm{M}$ U0126, $2.5 \mu \mathrm{M}$ bis1, $7 \mu \mathrm{M}$ Y-27632, or $0.1 \mu \mathrm{M}$ rotenone.

Data were normalized to untreated control cells and are displayed as means \pm SEM from 3 independent experiments. ${ }^{*} p<0.05$ vs. untreated control.

(C) TurboRFP expressing LUHMES were mixed with wtLUHMES at a ratio of 2:98 at the time of replating and were differentiated for an additional 3 days in the presence of $50 \mathrm{nM}$ rotenone and $25 \mathrm{nM}$ narciclasine. On the left, Hoechst-stained nuclei are shown together with an overlay of RFP-positive neurite traces. On the right, turboRFP positive cells with automatically identified and traced neurites are shown. An algorithm detects all RFP positive cells and creates a mask from each valid cell body (blue mask). Neurites are traced outward from each cell body (blue and red masks), analyzed, and validated against object selection parameters (like total neurite length, neurite branch points, or neurite cross points). 
of Rho A, and negatively influences neurite outgrowth. The pesticide rotenone triggers parkinsonian symptoms in rats (Sherer et al., 2003). At the concentration used, it did not affect cellular ATP levels (not shown), but mitochondrial function may have been subtly affected. We found that a combination of these two compounds leads to an inhibition of neurite outgrowth without causing general cytotoxicity, as can be seen from the strong RFP signal and the absence of apoptotic nuclei (Fig. 3C). The representative images indicate that the structure of neurites clearly can be detected and can serve not only as a sensitive parameter of neurotoxicity but also may enable studies on the single cell level in an environment of standard LUHMES cell densities.

\section{Localization of fluorescently labeled proteins in LUHMES}

Localization of a protein in a cell has a fundamental influence on its biological function, and this applies in particular to the situation of neurons with spatially extended neurites. For mechanistic studies, a cell model needs to allow overexpression of fluorescent fusion proteins to study localization in live cells. For example, we have chosen the protein wld(s) (Wallerian degeneration, slow) that was originally identified in mice displaying delayed Wallerian degeneration (Lunn et al., 1989). We have chosen the wld(s) protein as it represents an illustrative target where localization plays a vital role for its biological function.
The constructs generated and the optimized protocol for transduction are intended as a tool for interested researchers. The murine wld(s) protein is the result of a spontaneous duplication of a region on chromosome 4 leading to the expression of a protein composed of an N-terminal 70 aa sequence of Ube4b (N70) that is linked via an 18 aa sequence to the enzyme nicotinamide mononucleotide adenylyltransferase (NMNAT-1) (Mack et al., 2001; Coleman et al., 1998). It retains the nuclear localization sequences of the NMNAT1 protein and only a small portion of the protein can be found in the axons.

This fusion protein has powerful neurite-protective properties in vivo and in vitro (Conforti et al., 2007; Beirowski et al., 2009; Babetto et al., 2010). Expression of wld(s) in LUHMES may help to answer the question whether such neurite protection may also be observed in human cells. Unmodified LUHMES may be directly compared to LUHMES expressing the wld(s) protein. For initial studies on murine wld(s) in human cells, localization was examined by using wld(s)-GFP fusion constructs. The eGFP protein was stably fused to the C-terminus of the wld(s) protein. Expression of this construct in LUHMES allowed the detection of wld(s) in the cell by detection of eGFP fluorescence. As shown earlier for murine cells (Wilbrey et al., 2008), the wld(s) protein preferentially localized to the nucleus and accumulated in distinct subnuclear areas (Fig. 4A-D). To illustrate that eGFP fluorescence

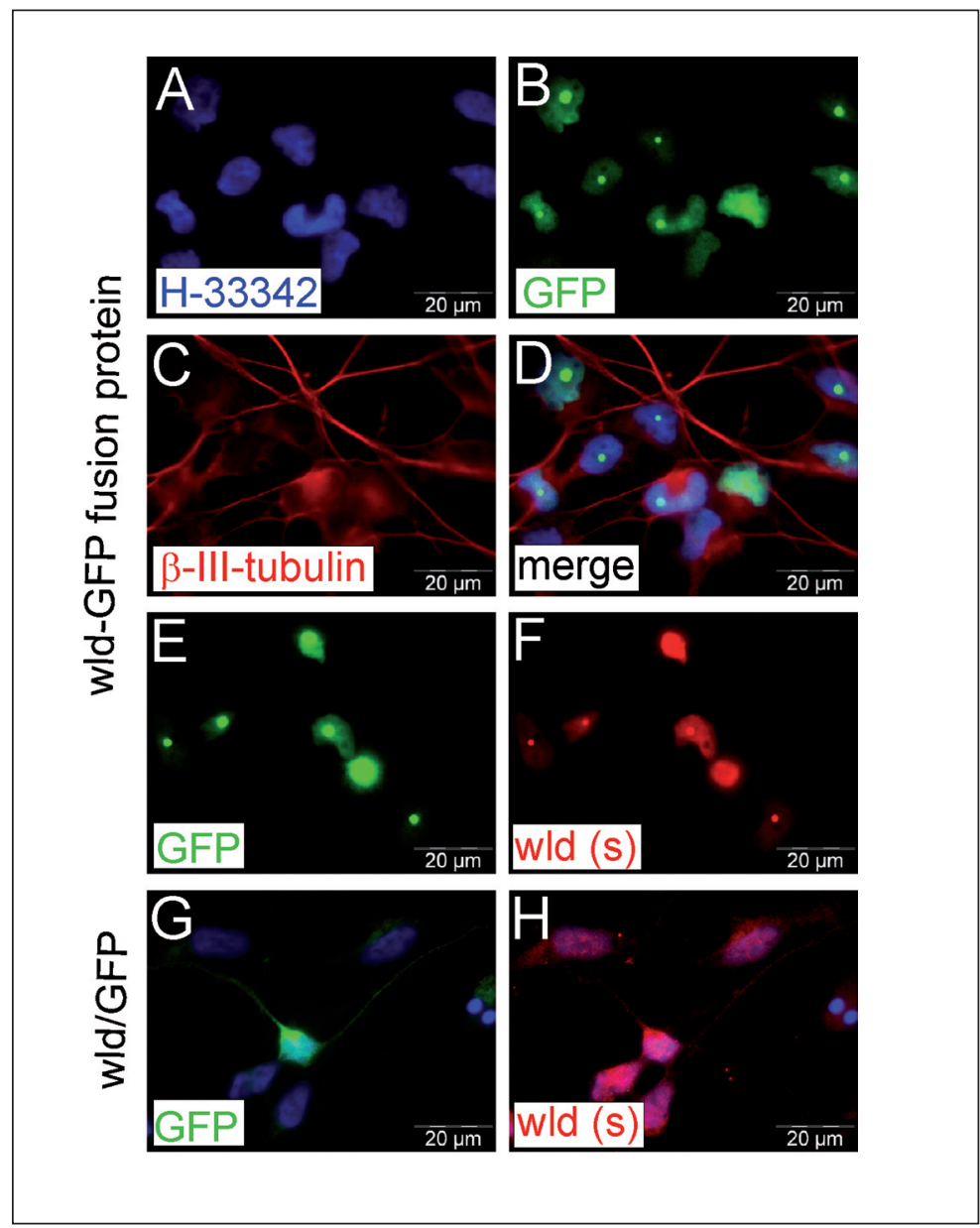

Fig. 4: Expression of different wld(s) protein variants as an example for protein targeting and fusion protein use

Proliferating LUHMES were incubated for $24 \mathrm{~h}$ with lentivirus particles coding for a wld(s)-eGFP stable fusion protein that allows live detection of wld(s) localization within a cell. WId(s)-eGFP expressing cells were selected by FACS, replated, and differentiated according to the standard differentiation protocol. (A-D) For visualization, fixed and permeabilized cells were stained with an anti- $\beta$-III-tubulin antibody. Merging of chromatin staining (Hoechst $\mathrm{H}$-33342) and eGFP fluorescence indicates a defined subnuclear localization of wld(s). (E-F) LUHMES expressing the wld(s)-eGFP fusion protein were stained with an anti-wld(s) antibody. Comparison with eGFP fluorescence indicates that the eGFP signal is representative of wld(s) localization within nuclei. (G-H) To test re-targeting, LUHMES were transfected with eGFP-Ubi-axonal wld(s). In this mutated wld(s) form, a peptide coding sequence from the amyloid precursor protein with two point mutations in the NMNAT nuclear localization sequence (R213A and R215A) was inserted downstream of the wld(s) gene to enable localization in axons. GFP fluorescence as well as antibody staining of wld(s) indicate a distribution of the mutated wld(s) form in the cell bodies, and in the neurites, while nuclear spots were absent. 
directly represents localization of wld(s) in the cell, wld(s) was stained with an antibody and exhibited the same staining pattern as observed with eGFP fluorescence (Fig. 4E,F). In order to experimentally force localization of wld(s) in neurites, a second construct was generated coding for a mutated form of wld(s) that would allow localization in neurites. On the N-terminus, a 15 aa sequence from amyloid precursor protein (APP) was introduced, as this peptide sequence is known for its role as axonal targeting motif. To reduce the intrinsic nuclear targeting of wld(s), two point mutations in the NMNAT-1 region (R213A; R215A) were introduced (Beirowski et al., 2009; Babetto et al., 2010). Localization of this mutated wld(s) protein was assessed both by eGFP detection and by wld(s) antibody staining (Fig. 4G,H). In comparison to the normal wld(s) protein (Fig. 4E,F) that displays a discrete localization in subnuclear regions, mutated wld(s) localized in the entire cell body and in neurites. With this system, the influence of different localizations of wld(s) in human neurons may be directly correlated to neurite integrity following exposure of the cells to different neurodegenerative compounds or axotomy.

\section{Overexpression of ASYN in LUHMES}

ASYN is one of the key proteins associated with Parkinson's disease (for review see Schildknecht et al., 2013). From familial forms of the disease, it is known that ASYN expression levels can affect the onset and progression of the disease (Singleton et al., 2003). It was therefore desirable to generate human neuronal cells with elevated ASYN levels. For this reason, a stable ASYN overexpressing LUHMES line was generated by use of the eGFP-Ubi-ASYN-myc construct (Fig. 5A). Fully differentiated (d6) wildtype and eGFP-Ubi-ASYN-myc expressing LUHMES were compared with respect to their mRNA expression of a set of dopaminergic markers. ASYN mRNA expression was significantly higher in transgenic cells than in wildtype LUHMES. All other markers investigated were not altered by ASYN overexpression (Fig. 5B). These observations indicate that the general phenotype of the cells and their differentiation capacity was not affected by the overexpression of ASYN. For further characterization, the levels of ASYN protein were analyzed throughout the course of the differentiation. On western blots, endogenous ASYN was distinguishable from ectopically expressed protein on the basis of protein size (overexpressed protein displayed a higher molecular weight as it was myc-tagged). Already in proliferating cells (d0), ASYN expressed from the lentiviral vector was clearly visible in the western blot (Fig. 5C). It increased further and reached a plateau of maximal expression after ca. 3 days of differentiation. Densitometric scans of the blots suggested that the overall ASYN levels were increased 3-10 fold by the viral expression. Tyrosine hydroxylase (TH) was cho-
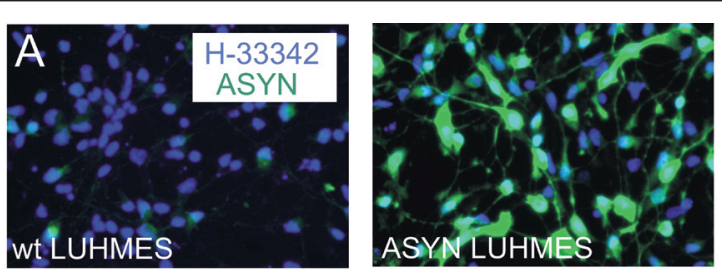

B

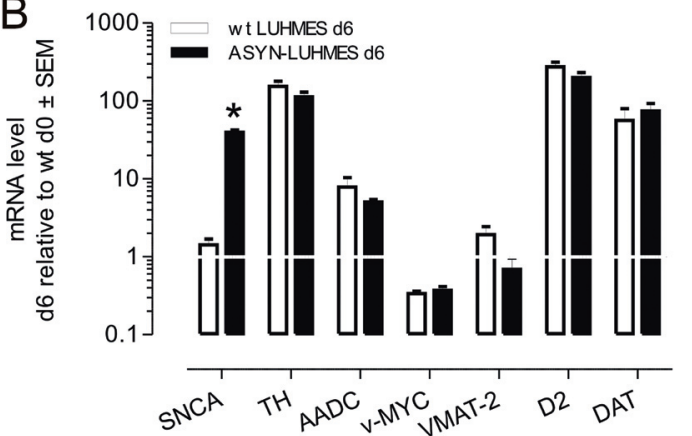

C
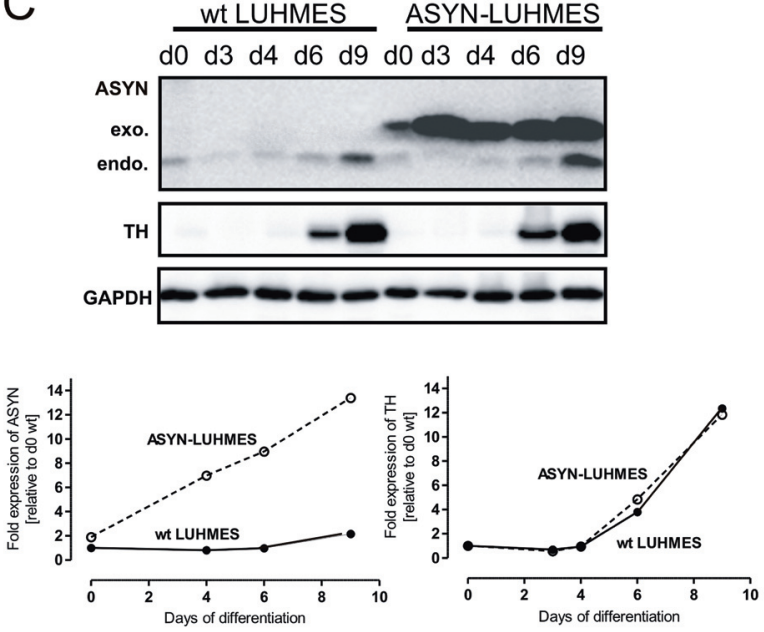

Fig. 5: Generation of stably ASYN overexpressing LUHMES

(A) Representative images of differentiated (d6) wildtype (wt) LUHMES and ASYN LUHMES (d6). Cells were fixed, permeabilized, and stained with an anti-ASYN antibody, and nuclei were stained with Hoechst $\mathrm{H}-33342$. For direct comparison, both images were taken with the same exposure time. (B) Wildtype LUHMES or ASYN-overexpressing LUHMES were differentiated for 6 days. RNA was extracted, and gene expression levels were detected by RT-qPCR. Expression levels are indicated relative to the gene expression at day 0 of wt LUHMES. (C) Wildtype LUHMES or LUHMES that express myc-tagged ASYN and GFP (GFP-Ubi-ASYN-myc) were differentiated for the time intervals indicated, cells were harvested, and protein was analyzed by western blot. ASYN originating from overexpression (ectopic) contained a C-terminal myc-tag and ran at a higher molecular weight $(29 \mathrm{kDa})$ than endogenous ASYN (17 kDa). Tyrosine hydroxylase (TH) was analyzed as an ASYN-independent marker for direct comparison of both LUHMES clones. GAPDH served as loading control. The graphs show a quantitative evaluation of protein expression of 3 independent experiments. Data are means $\pm S E M$ of three independent differentiations. Abbreviations: SNCA, synuclein, alpha gene; TH, tyrosine hydroxylase; AADC, amino acid decarboxylase; v-myc, myelocytomatosis viral related oncogene (avian); VMAT-2, vesicular monoamine transporter; D2, dopamine receptor D2; DAT, dopamine transporter. 
sen as independent marker of dopaminergic neurons; its protein levels in normal and ASYN-overexpressing LUHMES showed no difference. This observation corroborates our earlier findings (Fig. 2B and 5B) that expression of a G.O.I in LUHMES does not necessarily alter key phenotypic features of the cells. Most importantly, these findings suggested that overexpression of wildtype ASYN did not affect LUHMES viability. As subtle cytotoxic effects may be missed when the overall viability of cell preparations is compared at different time points, we developed a ratiometric method for a direct comparison. For this purpose, we generated a wildtype LUHMES subclone, stably expressing tRFP. The GFP-Ubi-ASYN LUHMES were mixed with the tRFP-LUHMES at a 50:50 ratio (Fig. 6A). This approach allowed a direct comparison of ASYN expressing cells (green fluorescence) with wildtype cells (red fluorescence) within the same well. The ratio of GFP and tRFP was followed over time, and it remained constant. Treatment of the mixed cultures with $\mathrm{MPP}^{+}$revealed a similar time dependent degeneration in both wildtype and ASYN expressing cells, i.e., the ratio of red and green cells was not changed by the treatment (not shown). This was confirmed in many different experiments, also including prolonged culture over two weeks.

\section{Effects of different ASYN expression levels on cell survival}

For an analysis of the influence of ASYN expression levels on the viability of $\mathrm{MPP}^{+}$-treated LUHMES, the cells were infected with a construct coding for ASYN, linked to GFP by the Ubi sequence in order to obtain fluorescently labeled cells in which ASYN is separated from the GFP protein. A homogenous culture of ASYN overexpressing cells was generated to ensure similar ASYN expression in all cells. The ASYN-LUHMES were directly compared with wildtype LUHMES with respect to their response towards varying concentrations of $\mathrm{MPP}^{+}$. Following a $60 \mathrm{~h}$ incubation period, no significant differences between the two cell lines were detected (Fig. 6B). In order to further validate these observations, ratiometric measurements, as described in Figure 6A, were used.
In ASYN overexpressing cells, an increased susceptibility towards $\mathrm{MPP}^{+}$or other toxins was initially expected. One explanation for the lack of difference could be the already high expression levels of endogenous ASYN. Wildtype LUHMES could hence represent a model of already elevated ASYN-mediated vulnerability. In this case it would be expected that siRNAmediated knockdown of endogenous ASYN would render cells less susceptible to $\mathrm{MPP}^{+}$. As an alternative explanation for the absence of effects of ASYN expression, it could be speculated that assessing general cell viability following an acute $\mathrm{MPP}^{+}$intoxication represents inappropriate experimental conditions for analyzing subtle differences, e.g., in neurite integrity, between wildtype and ASYN overexpressing cells. For future studies it would seem interesting to generate stable ASYN mutant clones (e.g., A30P; A53T). Based on observations in the literature, the mutant forms might allow the detection of significant differences when compared with LUHMES expressing wildtype ASYN or no additional ASYN at all. In cellular in vitro models, no consistent relationship between ASYN overexpression and neurotoxicity can be deduced from the literature (Zhu et al., 2012; Lee et al., 2001). Knockdown of endogenously expressed ASYN, however, regularly resulted in an, at least partial, protection from toxic insult (Zhu et al., 2012; Wu et al., 2009; Fountaine and Wade-Martins, 2007).

For further investigations of this concept, endogenous ASYN was downregulated by a siRNA-based approach. LUHMES were predifferentiated for 2 days and the differentiation process was continued in the presence of two different siRNAs against ASYN (ASYN1 and ASYN2). After 4 days of siRNA treatment, endogenous ASYN expression was significantly reduced (Fig. 7A). Without additional treatment, siRNA treated cells displayed the same phenotype as untreated control cells. The set of marker genes listed in Figure 2B was analyzed on the mRNA level. Addition of anti-ASYN siRNA had no significant influence on the expression of these targets (not shown). Although not a proof for other off-target effects, these observations point to a relative selective downregulation of ASYN. For an assessment of the bio-

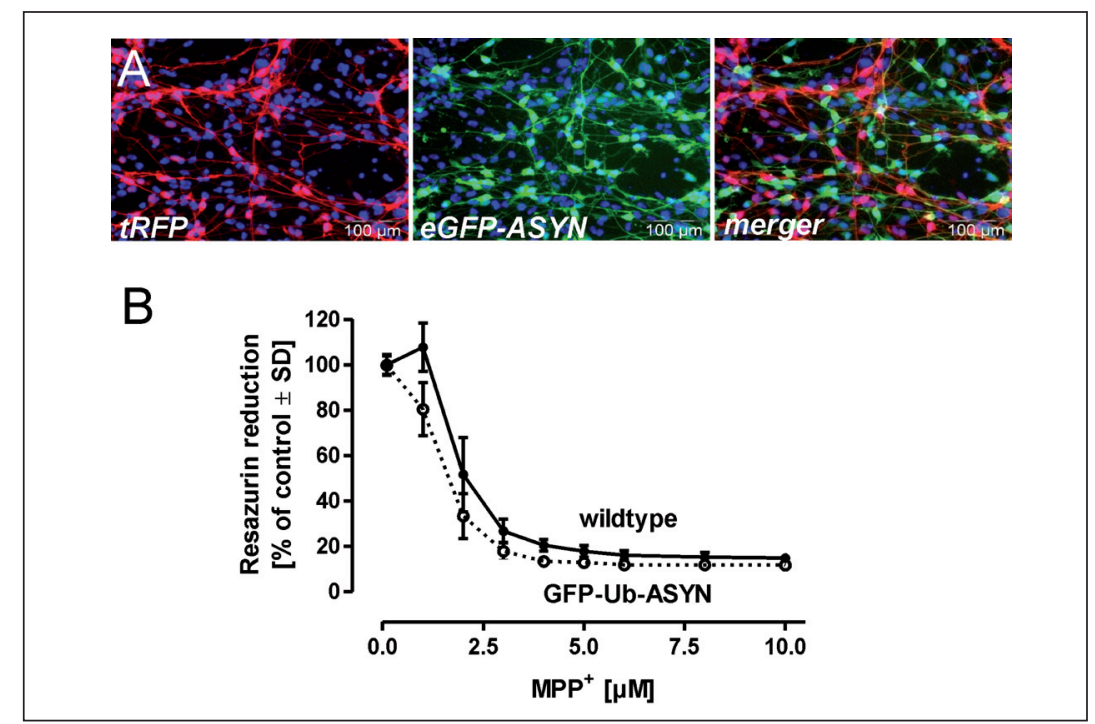

Fig. 6: High tolerance of LUHMES cells towards elevated ASYN levels

(A) A mixed culture of LUHMES expressing either tRFP or ASYN-eGFP is shown in single channels and as a merged image. Only green cells contain the disease gene, their behavior can be compared to wildtype neighbors, and the ratio of fluorescent proteins can be quantified. (B) Cultures of differentiated wildtype cells (day 6) and differentiated cells overexpressing GFP-Ub-ASYN were treated for $60 \mathrm{~h}$ with the parkinsonian toxin $\mathrm{MPP}^{+}$at the concentrations indicated. Viability was assessed by the resazurin reduction assay. Comparison of wildtype and GFP-Ub-ASYN LUHMES indicate no significant differences in their response to $\mathrm{MPP}^{+}$. Data are means $\pm \mathrm{SD}$ from triplicates. 
logical role of decreased endogenous ASYN levels, LUHMES with or without siRNA treatment were incubated with $\mathrm{MPP}^{+}$. Cells with a decreased ASYN expression were more resistant against $\mathrm{MPP}^{+}$toxicity (Fig. 7B,C). With respect to the high tolerance of LUHMES towards overexpression of wildtype ASYN, it needs to be discussed that ASYN indeed is not necessarily a cytotoxic protein. Transgenic mice, overexpressing ASYN or its mutant forms (e.g., A30P, A53T), usually do not show neurodegeneration, but some reports indicate an elevated susceptibility following exposure to neurotoxic conditions such as MPTP treatment (Dong et al., 2002; Nieto et al., 2006; Yu et al., 2008). However, others could not detect different susceptibilities between wildtype and ASYN overexpressing mice (Rathke-Hartlieb et al., 2001). Several reasons could account for such discrepancies, such as the MPTP treatment regimen applied. A study comparing the response toward MPTP in ASYN knockout mice and in a mouse strain that is characterized by a spontaneous loss of the ASYN gene, illustrated the fundamental influence of the respective mouse strain's genetic background on the outcome of the study. While ASYN knockout mice (C57BI/J) were partially protected against MPTP, mice with the spontaneous loss of ASYN (C57BL/6S) (Specht and Schoepfer, 2001) displayed no protection (Schlüter et al., 2003). Some studies even report protective effects of elevated ASYN levels (Manning-Bog et al., 2003; Kaul et al., 2005). For instance, mice exposed to the redox cy- cler paraquat, displayed an accumulation of protein aggregates, but were protected from neurotoxicity when they overexpressed wildtype or A53T ASYN in the substantia nigra. High levels of ASYN may serve as a reversible "antioxidant" (Schildknecht et al., 2013). Oxygen radicals may be neutralized by methionine sulfoxidation of ASYN. This is a reversible process due to the presence of the enzyme methionine sulfoxide reductase, allowing a reduction of the sulfoxidized methionine back to its native form (Maltsev et al., 2013). ASYN's interaction with mitochondria, or with the DAT, has been reported to limit the uptake of $\mathrm{MPP}^{+}$(Lehmensiek et al., 2002). This would explain the protective effects observed in ASYN overexpression experiments (Zhu et al., 2012; Fountaine and Wade-Martins, 2007). In the LUHMES model, neuronal uptake of $\mathrm{MPP}^{+}$was compared between wildtype cells, cells overexpressing ASYN, and ASYN knockdown cells. It was exactly the same under all conditions (not shown). Similar observations were made with intracellular ATP levels that were all similar under the conditions investigated (not shown).

\section{Inhibition of mitochondrial movement in neurites as early ef- fect of $M P P^{+}$}

The transport dynamics of mitochondria in neurites can serve as a sensitive readout for neuronal function (Büeler, 2009). In order to study the migration of single mitochondria, a LUHMES subclone was generated that stably expresses eGFP and, at the

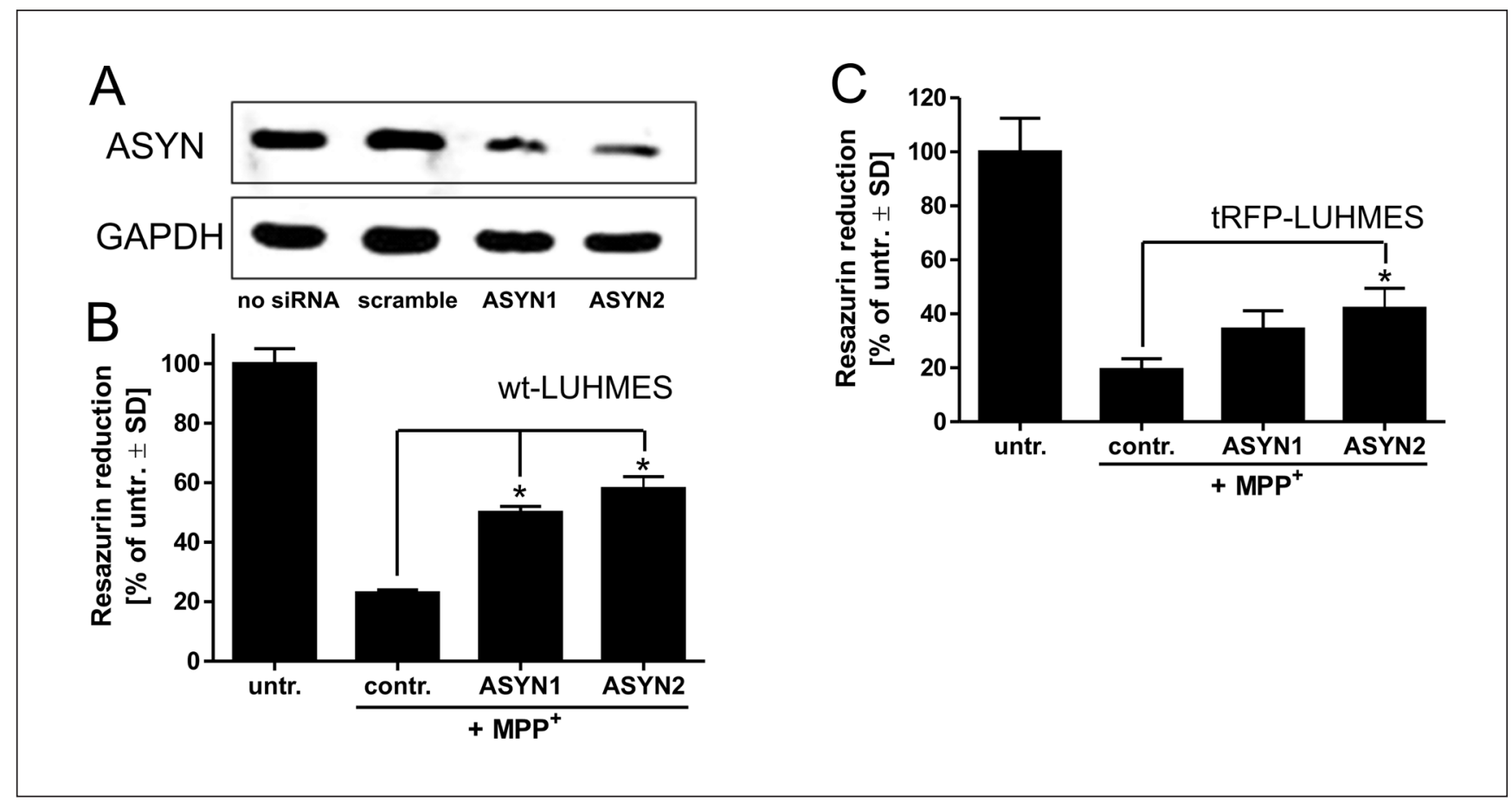

Fig. 7: Altered sensitivity to MPP+ by siRNA-mediated knockdown of endogenous ASYN

(A) Wildtype LUHMES were predifferentiated for 2 days and replated in the presence of $50 \mathrm{nmol}$ siRNA in 6 -well plates ( $2 \mathrm{ml}$ volume) for a further 4 days. Two siRNA sequences (ASYN1 and ASYN2) as well as a scramble sequence to exclude off-target effects, were applied. Cells were then lysed, subjected to Western blot analysis, and stained with an anti-ASYN antibody, GAPDH served as loading control. $(\mathrm{B}+\mathrm{C})$ Wildtype or tRFP expressing LUHMES, differentiated in the presence of siRNA as in $(\mathrm{A})$ were treated with $\mathrm{MPP}^{+}(5 \mu \mathrm{M})$ at day 6 of differentiation for a further $60 \mathrm{~h}$. Then, viability was assessed by the resazurin reduction assay. Untreated cells received neither siRNA nor MPP+. 
same time, tRFP that locates to mitochondria due to its fusion with a mitochondrial target sequence. Similar to the application of RFP-LUHMES for single cell neurite detection, analysis of mitochondria in a single, defined neurite requires a mixture of fluorescently labeled LUHMES with unlabeled LUHMES. This method allows an identification of single cells and their corresponding neurites within the environment of normal (high) cell density. A $100 \mu \mathrm{m}$ long segment of a neurite was defined as ROI and sequential images covering this ROI were taken over a period of $4 \mathrm{~min}$ (Fig. 8A). With this method, the anterograde or retrograde migration of single mitochondria was followed (Fig. $8 \mathrm{~B}$ ). Graphical display of the migrated distance ( $\mathrm{x}$-axis) vs. time (y-axis) allowed the calculation of individual mitochondrial ve- locities (distance/time) (Fig. 8B,C). With this model, the effect of the parkinsonian toxin $\mathrm{MPP}^{+}$on mitochondria in neurites was investigated. $\mathrm{MPP}^{+}$was used at a medium concentration of $5 \mu \mathrm{M}$ as in previous publications (Schildknecht et al., 2009). Under these conditions, it is rapidly taken up by LUHMES cells via the DAT with a half maximal uptake after roughly $45 \mathrm{~min}$ (Scholz et al., 2011). It was recently demonstrated that a significant decline of intracellular ATP levels cannot be detected earlier than about 24 $\mathrm{h}$ after the onset of $\mathrm{MPP}^{+}$treatment. Comparison of $\mathrm{MPP}^{+}$treated cells with untreated controls after $24 \mathrm{~h}$ revealed a reduction in the total number of mitochondria in neurites (Fig. 8D), and a significant reduction in velocity (anterograde + retrograde) (Fig. $8 \mathrm{E}, \mathrm{F})$. Direct comparison of the direction of transport indicated

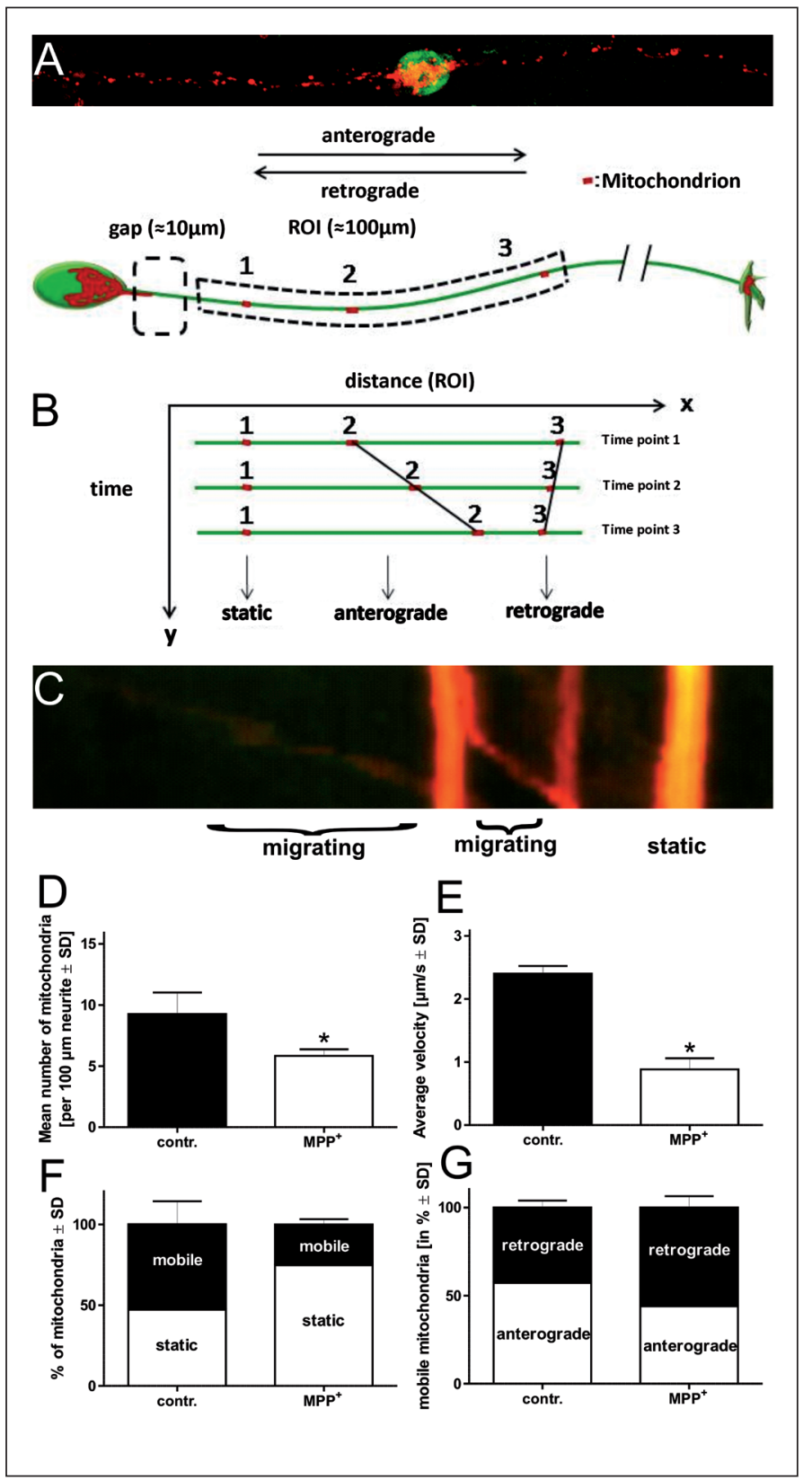

\section{Fig. 8: Quantification of mitochondrial transport} in neurites

(A) Mitochondrial transport was assessed in mixed cultures of $4 \%$ eGFP mito-tRFP-expressing LUHMES mixed with $96 \%$ wildtype LUHMES. This method allows the detection of single neurites at standard cell densities. LUHMES cell bodies and neurites appear in green (eGFP); mitochondria within the same cells are colored in red (tRFP). An example cell shows mitochondrial distribution along neurites. GFP is mainly seen in the cell body at the short exposure time chosen.

(B) Movement of single mitochondria in neurites was detected in a $100 \mu \mathrm{m}$ long region of interest (ROI) along a single neurite with a gap of $10 \mu \mathrm{m}$ between the cell body and the neurite. The ROI was manually defined (ImageJ software; $\mathrm{NIH}$ ). Three example mitochondria are shown on the scheme. Time-lapse imaging was performed over a period of $4 \mathrm{~min}$ in $13 \mathrm{~s}$ intervals.

For evaluation of movement, kymographs were produced: the $\mathrm{ROI}$ was plotted on the $\mathrm{x}$-axis versus time on the $y$-axis for each recorded timepoint.

(C) Example kymograph: Fused images of mitochondria over time yield vertical lines for static mitochondria and diagonal lines for anterograde, respectively retrograde, mitochondrial movement. For calculating mitochondrial velocity, the slope of diagonal lines was calculated by an ImageJ-based makro generated by the Bioimaging Center (BIC), University of Konstanz.

(D) Differentiated (d6) LUHMES stably expressing eGFP/ mito-tRFP, were treated with $\mathrm{MPP}^{+}(5 \mu \mathrm{M})$ for $24 \mathrm{~h}$. Mean mitochondrial numbers were detected in randomly selected $100 \mu \mathrm{m}$ ROI.

(E). All migrating mitochondria (anterograde + retrograde) within this ROI were analyzed. Velocity for each single mitochondrion was calculated, and mean values are illustrated.

(F) Among all mitochondria detected in the ROI, the number of static and mobile (anterograde + retrograde) mitochondria was detected in control cells as well as in MPP ${ }^{+}$treated cells.

(G) Within the ROI, all migrating mitochondria were identified and the percentage moving in an anterograde, respectively retrograde, direction in control and $\mathrm{MPP}^{+}$-treated cells was detected. All experiments were repeated at least three times independently. In each experimental setup, ten or more mitochondria were analyzed. ${ }^{*} p<0.05$ vs. control. 
an elevated retrograde transport (Fig. 8G) in $\mathrm{MPP}^{+}$-treated cells. This may explain the reduced total number of mitochondria in neurites and suggests an accumulation of mitochondria in the cell body, where fission/fusion processes or even mitophagy could take place (Knott et al., 2008). In a next step, the time course of $\mathrm{MPP}^{+}$-mediated changes in mitochondrial mobility was investigated. Only $2 \mathrm{~h}$ after $\mathrm{MPP}^{+}$treatment, a shift from mobile to static mitochondria was observed, and this behavior became more pronounced with longer incubation periods (Fig. 9A,B).

Following the observation of the early $\mathrm{MPP}^{+}$-mediated effect on mitochondrial movement, we addressed the question of a potential mechanism operating independent of ATP depletion (Pöltl et al., 2012). In addition to its inhibitory action on mitochondrial complex I, $\mathrm{MPP}^{+}$promotes oxidative stress conditions (Seaton et al., 1997). Ascorbic acid (vitamin C) was identified in previous LUHMES studies as protective against $\mathrm{MPP}^{+}$toxicity (Schildknecht et al., 2009). Therefore, $\mathrm{MPP}^{+}$was applied here in combination with vitamin $\mathrm{C}$, and a partial protection from $\mathrm{MPP}^{+}$dependent mitochondrial immobilization in neurites (Fig. 9C) as well as from the drop in mitochondrial numbers (Fig. 9D) in neurites, was detected. The early effect of $\mathrm{MPP}^{+}$ on mitochondrial migration $(2-6 \mathrm{~h})$ in neurites that we have ob- served here deserves particular attention, as it could represent a sensitive marker for substances and conditions that influence neuronal integrity.

The focus of most of the herein introduced work on the genetic manipulation of LUHMES was on lentiviral transduction. The choice of this technology is based mostly on our initial observations that methods such as lipofection yielded only poor transfection efficiencies. In parallel to our lentiviral work, we now optimized an AMAXA-based nucleofection protocol. In Figure 10, a construct coding for the transcription factor ATF-4 (Activating Transcription Factor 4) with luciferase as downstream readout was transfected (Vattem and Wek, 2004). Co-nucleofection of a GFP plasmid allowed a rapid estimate of the transfection efficiency (Fig. 10A,B). In order to demonstrate the function of a reporter assay in LUHMES cells, the transfected cells were treated with the proteasome inhibitor MG-132 to trigger ATF-4 activation (Fig. 10C). These experiments illustrate that the ATF-4/luciferase plasmid (Vattem and Wek, 2004) serves as a relatively sensitive readout for ATF-4 activation in LUHMES and also show that AMAXA-based lipofection can be regarded as a potential alternative approach for plasmid transfection into LUHMES.

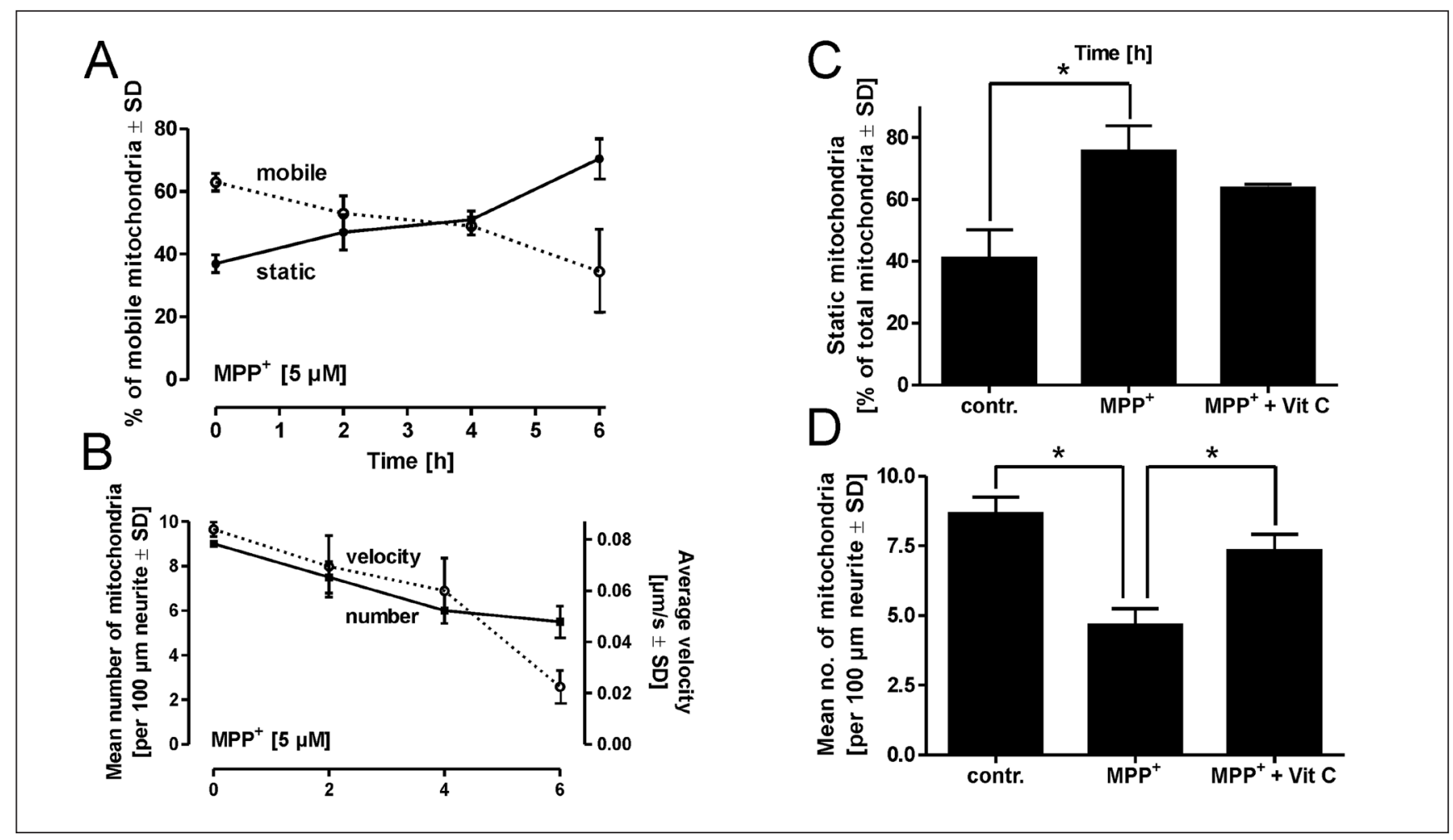

Fig. 9: Rapid reduction of mitochondrial migration by MPP+

Mixed cultures of $4 \%$ eGFP/mito-tRFP and $96 \%$ wt LUHMES were treated with MPP $^{+}(5 \mu \mathrm{M})$ for the time intervals indicated. (A) Among all mitochondria within the $100 \mu \mathrm{m}$ ROI, the proportions of static and mobile mitochondria were detected. (B) The mean number of mitochondria, as well as their respective velocity (anterograde + retrograde) was detected. $(\mathrm{C}+\mathrm{D})$ For pharmacological intervention of $\mathrm{MPP}^{+}$mediated changes in mitochondrial movement, cells were treated with $\mathrm{MPP}^{+}(5 \mu \mathrm{M})$ in the presence or absence of vitamin $\mathrm{C}(1$ $\mathrm{mM}$ ) for $24 \mathrm{~h}$. The number of static mitochondria, and the number of mitochondria in the ROI was detected. All experiments were repeated at least three times independently. In each experimental setup, ten or more mitochondria were analyzed.

${ }^{*} p<0.05$ vs. control. 

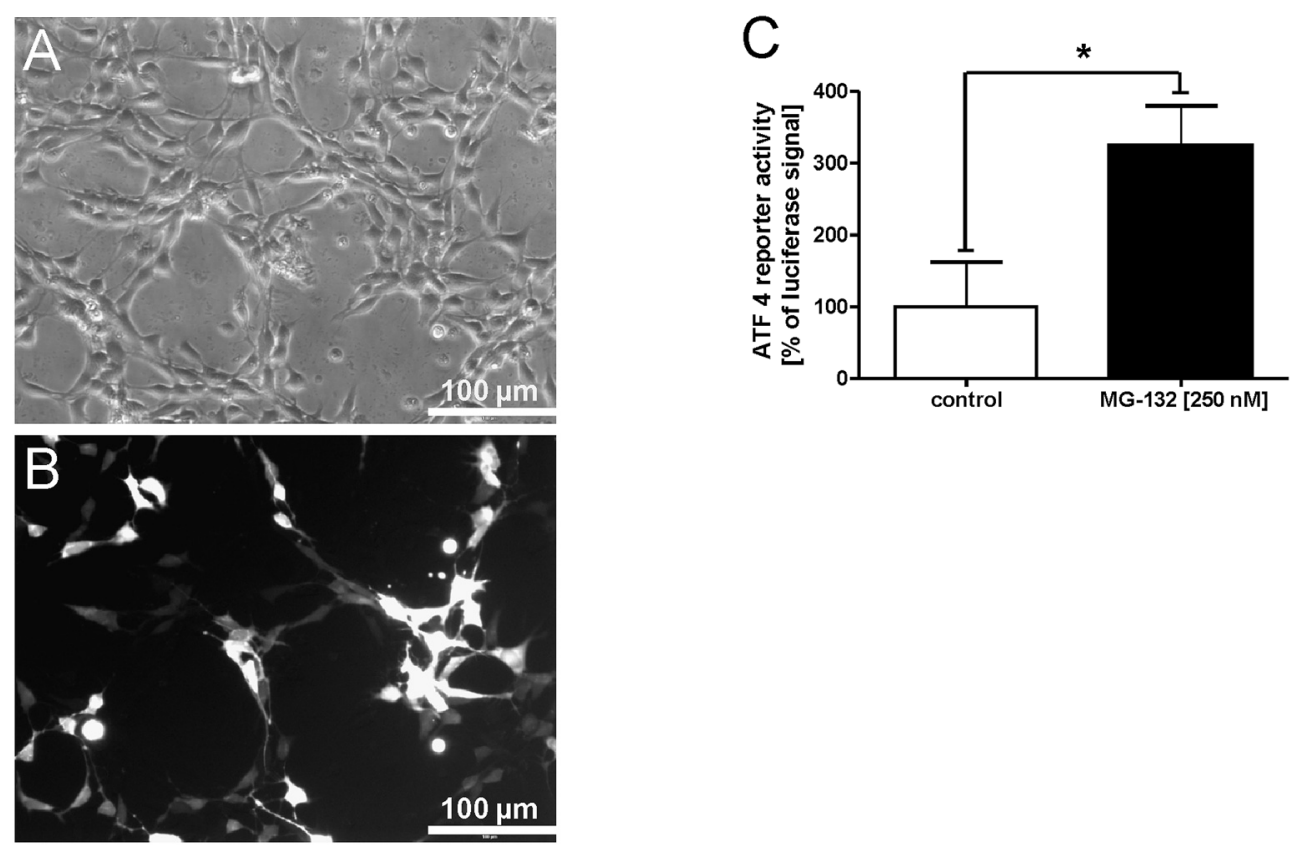

Fig. 10: AMAXA nucleofection with ATF4-Luc reporter plasmid

LUHMES were co-transfected with an ATF-Luc reporter plasmid and the GFP control plasmid at a ratio of 1:1 using an AMAXA nucleofector device.

(A) Phase contrast image of LUHMES $16 \mathrm{~h}$ post transfection.

(B) GFP fluorescent cells $16 \mathrm{~h}$ post transfection.

(C) Cells were treated at day 6 of differentiation with the proteasome inhibitor MG-132 $(250 \mathrm{~nm})$ to induce ATF4 translation. Luciferase activity was measured $6 \mathrm{~h}$ later. Luciferase activity is depicted relative to control. Data are means $\pm \mathrm{SD}$ from triplicates. ${ }^{*} p<0.01$.

\section{Conclusions and outlook}

In the present manuscript, we have described optimized protocols of lentiviral gene transfer into the human neuronal cell line LUHMES. This method allowed a reproducible and efficient integration of a G.O.I. into LUHMES. We furthermore described examples of stable subclones of genetically modified LUHMES. Our findings suggest a broad potential for the use of such cell cultures in basic research, and also for neurodevelopmental or neurotoxicity screening assays performed traditionally in transgenic animals.

The expression of a mitochondrially targeted fluorescence group in a stable LUHMES subclone offers new possibilities in neurotoxicity research. Although not yet tested with a large battery of known neurotoxicants, mitochondrial migration in a human in vitro model could represent a new highly sensitive assay system covering the low concentration ranges of compounds that display no effect in more insensitive classical cell toxicity assays. In the future, a combination of reporter approaches with the expression of genes relevant to toxicity or diseases will be important. An example would be the combination of mitochondrial mobility as readout and variations in ASYN as G.O.I. Ideally, this would be performed with inducible expression systems and be combined with high content imaging and new omics approaches.

\section{References}

Babetto, E., Beirowski, B., Janeckova, L., et al. (2010). Targeting NMNAT1 to axons and synapses transforms its neuroprotective potency in vivo. J Neurosci 30, 13291-13304.

Basketter, D. A., Clewell, H., Kimber, I., et al. (2012). A roadmap for the development of alternative (non-animal) methods for systemic toxicity testing $-\mathrm{t}^{4}$ report. ALTEX 29, 3-91.

Beirowski, B., Babetto, E., Gilley, J., et al. (2009). Non-nuclear Wld(S) determines its neuroprotective efficacy for axons and synapses in vivo. J Neurosci 29, 653-668.

Berliocchi, L., Fava, E., Leist, M., et al. (2005). Botulinum neurotoxin $\mathrm{C}$ initiates two different programs for neurite degeneration and neuronal apoptosis. J Cell Biol 168, 607-618.

Biedler, J. L., Helson, L., and Spengler, B. A. (1973). Morphology and growth, tumorigenicity, and cytogenetics of human neuroblastoma cells in continuous culture. Cancer Res 33, 2643-2652.

Biedler, J. L., Roffler-Tarlov, S., Schachner, M., and Freedman, L. S. (1978). Multiple neurotransmitter synthesis by human neuroblastoma cell lines and clones. Cancer Res 38, 37513757.

Büeler, H. (2009). Impaired mitochondrial dynamics and function in the pathogenesis of Parkinson's disease. Exp Neurol 218, 235-246. 
Coleman, M. P., Conforti, L., Buckmaster, E. A., et al. (1998). An $85-\mathrm{kb}$ tandem triplication in the slow Wallerian degeneration (Wlds) mouse. Proc Natl Acad Sci U S A 95, 9985-9990.

Conforti, L., Fang, G., Beirowski, B., et al. (2007). NAD(+) and axon degeneration revisited: Nmnat1 cannot substitute for Wld(S) to delay Wallerian degeneration. Cell Death Differ 14, 116-127.

Dong, Z., Ferger, B., Feldon, J., and Büeler, H. (2002). Overexpression of Parkinson's disease-associated alpha-synuclein A53T by recombinant adeno-associated virus in mice does not increase the vulnerability of dopaminergic neurons to MPTP. J Neurobiol 53, 1-10.

Donnelly, M. L., Luke, G., Mehrotra, A., et al. (2001). Analysis of the aphthovirus $2 \mathrm{~A} / 2 \mathrm{~B}$ polyprotein "cleavage" mechanism indicates not a proteolytic reaction but a novel translational effect: a putative ribosomal "skip." J Gen Virol 82, 1013-1025.

Falsig, J., Latta, M., and Leist, M. (2004). Defined inflammatory states in astrocyte cultures: correlation with susceptibility towards CD95-driven apoptosis. J Neurochem 88, 181-193.

Fountaine, T. M. and Wade-Martins, R. (2007). RNA interference-mediated knockdown of alpha-synuclein protects human dopaminergic neuroblastoma cells from $\mathrm{MPP}(+)$ toxicity and reduces dopamine transport. J Neurosci Res 85, 351-363.

Greene, L. A. and Tischler, A. S. (1976). Establishment of a noradrenergic clonal line of rat adrenal pheochromocytoma cells which respond to nerve growth factor. Proc Natl Acad Sci U S A 73, 2424-2428.

Hansson, O., Castilho, R. F., Kaminski Schierle, G. S., et al. (2000). Additive effects of caspase inhibitor and lazaroid on the survival of transplanted rat and human embryonic dopamine neurons. Exp Neurol 164, 102-111.

Hatten, M. E. and Liem, R. K. (1981). Astroglial cells provide a template for the positioning of developing cerebellar neurons in vitro. J Cell Biol 90, 622-630.

Hatten, M. E. (1985). Neuronal regulation of astroglial morphology and proliferation in vitro. J Cell Biol 100, 384-396.

Jang, S. K., Kräusslich, H. G., Nicklin, M. J., et al. (1988). A segment of the 5' nontranslated region of encephalomyocarditis virus RNA directs internal entry of ribosomes during in vitro translation. J Virol 62, 2636-2643.

Johansson, C. B., Svensson, M., Wallstedt, L., et al. (1999). Neural stem cells in the adult human brain. Exp Cell Res 253, 733-736.

Karreman, C. (2002). AiO, combining DNA/protein programs and oligo-management. Bioinformatics 18, 884-885.

Kaul, S., Anantharam, V., Kanthasamy, A., and Kanthasamy, A. G. (2005). Wild-type alpha-synuclein interacts with proapoptotic proteins PKCdelta and BAD to protect dopaminergic neuronal cells against $\mathrm{MPP}^{+}$-induced apoptotic cell death. Brain Res Mol Brain Res 139, 137-152.

Knott, A. B., Perkins, G., Schwarzenbacher, R., and Bossy-Wetzel, E. (2008). Mitochondrial fragmentation in neurodegeneration. Nat Rev Neurosci 9, 505-518.

Kremer, M., Henn, A., Kolb, C., et al. (2010). Reduced immunoproteasome formation and accumulation of immunoproteasomal precursors in the brains of lymphocytic choriomeningitis virus-infected mice. J Immunol 185, 5549-5560.
Leander Johansen, J., Dagø, L., Tornøe, J., et al. (2005). A new versatile and compact lentiviral vector. Mol Biotechnol 29, 47-56.

Lee, G., Chambers, S. M., Tomishima, M. J., and Studer, L. (2010). Derivation of neural crest cells from human pluripotent stem cells. Nat Protoc 5, 688-701.

Lee, M., Hyun, D., Halliwell, B., and Jenner, P. (2001). Effect of the overexpression of wild-type or mutant alpha-synuclein on cell susceptibility to insult. J. Neurochem 76, 998-1009.

Lehmensiek, V., Tan, E. M., Schwarz, J., and Storch, A. (2002). Expression of mutant alpha-synucleins enhances dopamine transporter-mediated $\mathrm{MPP}^{+}$toxicity in vitro. Neuroreport 13, 1279-1283.

Leist, M., Kadereit, S., and Schildknecht, S. (2008). Food for thought ... on the real success of 3R approaches. ALTEX 25, 17-32.

Leist, M., Efremova, L., and Karreman C. (2010). Food for thought ... considerations and guidelines for basic test method descriptions in toxicology. ALTEX 27, 309-317.

Leist, M., Lidbury, B. A., Yang, C., et al. (2012). Novel technologies and an overall strategy to allow hazard assessment and risk prediction of chemicals, cosmetics, and drugs with animal-free methods. ALTEX 29, 373-388.

Lopes, F. M., Schröder, R., da Frota, M. L. Jr., et al. (2010). Comparison between proliferative and neuron-like SH-SY5Y cells as an in vitro model for Parkinson disease studies. Brain Res 1337, 85-94.

Lotharius, J., Barg, S., Wiekop, P., et al. (2002). Effect of mutant alpha-synuclein on dopamine homeostasis in a new human mesencephalic cell line. J Biol Chem 277, 38884-38894.

Lotharius, J., Falsig, J., van Beek, J., et al. (2005). Progressive degeneration of human mesencephalic neuron-derived cells triggered by dopamine-dependent oxidative stress is dependent on the mixed-lineage kinase pathway. J Neurosci 25, 6329-6342.

Lunn, E. R., Perry, V. H., Brown, M. C., et al. (1989). Absence of Wallerian degeneration does not hinder regeneration in peripheral nerve. Eur J Neurosci 1, 27-33.

Mack, T. G., Reiner, M., Beirowski, B., et al. (2001). Wallerian degeneration of injured axons and synapses is delayed by a Ube4b/Nmnat chimeric gene. Nat Neurosci 4, 1199-1206.

Maltsev, A. S., Chen, J., Levine, R. L., and Bax., A. (2013). Site-specific interaction between $\alpha$-synuclein and membranes probed by NMR-observed methionine oxidation rates. $J$ Am Chem Soc 135, 2943-2946.

Manning-Bog, A. B., McCormack, A. L., Purisai, M. G., et al. (2003). Alpha-synuclein overexpression protects against paraquat-induced neurodegeneration. J Neurosci 23, 30953099.

Matentzoglu, K. and Scheffner, M. (2009). Ubiquitin-fusion protein system: a powerful tool for ectopic protein expression in mammalian cells. Biotechniques 46, 21-28.

Nieto, M., Gil-Bea, F. J., Dalfó, E., et al. (2006). Increased sensitivity to MPTP in human alpha-synuclein A30P transgenic mice. Neurobiol Aging 27, 848-856.

Påhlman, S., Ruusala, A. I., Abrahamsson, L., et al. (1984). Retinoic acid-induced differentiation of cultured human neu- 
roblastoma cells: a comparison with phorbolester-induced differentiation. Cell Differ 14, 135-144.

Paul, G., Christophersen, N. S., Raymon, H., et al. (2007). Tyrosine hydroxylase expression is unstable in human immortalized mesencephalic cell line-studies in vitro and after intracerebral grafting in vivo. Mol Cell Neurosci 34, 390-399.

Pöltl, D., Schildknecht, S., Karreman, C., and Leist, M. (2012). Uncoupling of ATP-depletion and cell death in human dopaminergic neurons. Neurotoxicology 33, 769-779.

Rathke-Hartlieb, S., Kahle, P. J., Neumann, M., et al. (2001). Sensitivity to MPTP is not increased in Parkinson's diseaseassociated mutant alpha-synuclein transgenic mice. J Neurochem 77, 1181-1184.

Schildknecht, S., Pöltl, D., Nagel, D. M., et al. (2009). Requirement of a dopaminergic neuronal phenotype for toxicity of low concentrations of 1-methyl-4-phenylpyridinium to human cells. Toxicol Appl Pharmacol 241, 23-35.

Schildknecht, S., Pape, R., Müller, N., et al. (2011). Neuroprotection by minocycline caused by direct and specific scavenging of peroxynitrite. J Biol Chem 286, 4991-5002.

Schildknecht, S., Gerding, H. R., Karreman, C., et al. (2013). Oxidative and nitrative alpha-synuclein modifications and proteostatic stress: implications for disease mechanisms and interventions in synucleinopathies. J Neurochem 125, 491511.

Schlüter, O. M., Fornai, F., Alessandrí, M. G., et al. (2003). Role of alpha-synuclein in 1-methyl-4-phenyl-1,2,3,6-tetrahydropyridine-induced parkinsonism in mice. Neuroscience 118 , 985-1002.

Scholz, D., Pöltl, D., Genewsky, A., et al. (2011). Rapid, complete and large-scale generation of post-mitotic neurons from the human LUHMES cell line. J Neurochem 119, 957-971.

Scholz, D., Chernyshova, Y., and Leist, M. (2013). Control of $\mathrm{A} \beta$ release from human neurons by differentiation status and RET signaling. Neurobiol Aging 34, 184-199.

Seaton, T. A., Cooper, J. M., and Schapira, A. H. (1997). Free radical scavengers protect dopaminergic cell lines from apoptosis induced by complex I inhibitors. Brain Res 777, 110118.

Sherer, T. B., Betarbet, R., Testa, C. M., et al. (2003). Mechanism of toxicity in rotenone models of Parkinson's disease. $J$ Neurosci 23, 10756-10764.

Singleton, A. B., Farrer, M., Johnson, J., et al. (2003). AlphaSynuclein locus triplication causes Parkinson's disease. Science 302, 841.

Specht, C. G. and Schoepfer, R. (2001). Deletion of the alphasynuclein locus in a subpopulation of C57BL/6J inbred mice. BMC Neurosci 2, 11.

Stefanis, L. (2012). $\alpha$-Synuclein in Parkinson's disease. Cold Spring Harb Perspect Med 2, a009399.

Stiegler, N. V., Krug, A. K., Matt, F., and Leist, M. (2011). Assessment of chemical-induced impairment of human neurite outgrowth by multiparametric live cell imaging in high-density cultures. Toxicol Sci 121, 73-87. van Thriel, C., Westerink, R. H., Beste, C., et al. (2012). Translating neurobehavioural endpoints of developmental neurotoxicity tests into in vitro assays and readouts. Neurotoxicology 33, 911-924.

Vattem, K. M. and Wek, R. C. (2004). Reinitiation involving upstream ORFs regulates ATF4 mRNA translation in mammalian cells. Proc Natl Acad Sci U S A 101, 11269-11274.

Vergo, S., Johansen, J. L., Leist, M., and Lotharius, J. (2007). Vesicular monoamine transporter 2 regulates the sensitivity of rat dopaminergic neurons to disturbed cytosolic dopamine levels. Brain Res 1185, 18-32.

Wilbrey, A. L., Haley, J. E., Wishart, T. M., et al. (2008). VCP binding influences intracellular distribution of the slow Wallerian degeneration protein, Wld(S). Mol Cell Neurosci 38, 325-340.

Wu, F., Poon, W. S., Lu, G., et al. (2009). Alpha-synuclein knockdown attenuates MPP+ induced mitochondrial dysfunction of SH-SY5Y cells. Brain Res 1292, 173-179.

Yu, W. H., Matsuoka, Y., Sziráki, I., et al. (2008). Increased dopaminergic neuron sensitivity to 1-methyl-4-phenyl1,2,3,6-tetrahydropyridine (MPTP) in transgenic mice expressing mutant A53T alpha-synuclein. Neurochem Res 33, 902-911.

Zhu, M., Li, W., and Lu, C. (2012). Role of alpha-synuclein protein levels in mitochondrial morphology and cell survival in cell lines. PLoS One 7, e36377.

Zimmer, B., Schildknecht, S., Kuegler, P. B., et al. (2011a). Sensitivity of dopaminergic neuron differentiation from stem cells to chronic low-dose methylmercury exposure. Toxicol Sci 121, 357-367.

Zimmer, B., Kuegler, P. B., Baudis, B., et al. (2011b). Coordinated waves of gene expression during neuronal differentiation of embryonic stem cells as basis for novel approaches to developmental neurotoxicity testing. Cell Death Differ 18 , 383-395.

\section{Acknowledgments}

This work was supported by the Doerenkamp-Zbinden Foundation and the Collaborative Research Center 969 "Chemical and Biological Principles of Cellular Proteostasis," funded by the Deutsche Forschungsgemeinschaft (DFG).

\section{Correspondence to}

Stefan Schildknecht, $\mathrm{PhD}$

University of Konstanz

PO Box M657

78457 Konstanz

Germany

Fax: +497531885039

Phone: +497531885053

e-mail: Stefan.Schildknecht@uni-konstanz.de 